\title{
Structural basis for ligand recognition and $G$ protein-coupling promiscuity of the cholecystokinin A receptor
}

Qiufeng Liu ${ }^{1, *}$, Dehua Yang ${ }^{1,2,3,}$, Youwen Zhuang ${ }^{1, *}$, Tristan I. Croll ${ }^{4}$, Xiaoqing Cai ${ }^{3}$, Antao Dai ${ }^{3}$, Xinheng He $\mathrm{He}^{1,2}$, Jia Duan ${ }^{1,2}$, Wanchao Yin ${ }^{1}$, Chenyu Ye ${ }^{5}$, Fulai Zhou ${ }^{1}$, Beili Wu ${ }^{1,2,6,7}$, Qiang Zhao ${ }^{2,7,8}$, H. Eric Xu $\mathrm{Xu}^{1,2,6, \dagger}$, Ming-Wei Wang ${ }^{1,2,3,5,6,9, \dagger}$, Yi Jiang ${ }^{1,2, \dagger}$

1. The CAS Key Laboratory of Receptor Research, Shanghai Institute of Materia Medica, Chinese Academy of Sciences, Shanghai 201203, China

2. University of Chinese Academy of Sciences, Beijing 100049, China

3. The National Center for Drug Screening, Shanghai Institute of Materia Medica, Chinese Academy of Sciences, Shanghai 201203, China

4. Department of Haematology, Cambridge Institute for Medical Research, University of Cambridge, Cambridge CB2 0XY, U.K.

5. School of Pharmacy, Fudan University, Shanghai 201203, China

6. School of Life Science and Technology, ShanghaiTech University, Shanghai 201210, China

7. CAS Center for Excellence in Biomacromolecules, Chinese Academy of Sciences, Beijing 100101, China

8. State Key Laboratory of Drug Research, Shanghai Institute of Materia Medica, Chinese Academy of Sciences, Shanghai 201203, China

9. School of Basic Medical Sciences, Fudan University, Shanghai 200032, China

10. *These authors contributed equally: Qiufeng Liu, Dehua Yang, Youwen Zhuang

Correspondences: Y.J. (yijiang@simm.ac.cn), M.-W.W. (mwwang@simm.ac.cn), and H.E.X. (eric.xu@simm.ac.cn) 
Cholecystokinin A receptor $\left(\mathrm{CCK}_{\mathrm{A}} \mathrm{R}\right)$ belongs to family A $\mathrm{G}$ protein-coupled receptors (GPCRs) and regulates nutrient homeostasis upon stimulation by cholecystokinin (CCK). It is an attractive drug target for gastrointestinal and metabolic diseases. One distinguishing feature of $\mathrm{CCK}_{\mathrm{A}} \mathrm{R}$ is its ability to interact with sulfated ligand and to couple with divergent $G$ protein subtypes, including $G_{s}, G_{i}$, and $G_{q}$. However, the basis for $G$ protein coupling promiscuity and ligand recognition by $\mathrm{CCK}_{\mathrm{A}} \mathrm{R}$ remain unknown. Here we present three cryoelectron microscopy (cryo-EM) structures of sulfated CCK-8 activated $\mathrm{CCK}_{A} R$ in complex with $G_{s}, G_{i}$, and $G_{q}$ heterotrimers, respectively. In these three structures, $C_{C K} R$ presents a similar conformation, whereas conformational differences in "wavy hook" of Ga subunits and ICL3 of the receptor serve as determinants in G protein coupling selectivity. These structures together with mutagenesis data provide the framework for understanding the $G$ protein coupling promiscuity by $\mathrm{CCK}_{\mathrm{A}} \mathrm{R}$ and uncover the mechanism of receptor recognition by sulfated CCK-8.

Cholecystokinin (CCK) is one of the earliest discovered gastrointestinal hormones, participating in gallbladder contraction and pancreatic enzyme secretion. It also acts as a neurotransmitter and is extensively distributed throughout the nervous system ${ }^{1}$. Selective cleavage of CCK precursor produces a series of bioactive isoforms in different lengths, with CCK-58, -33, -22, and -8 comprising the major peptide fragments in humans. However, the carboxy-terminal octapeptide CCK-8 (DYMGWMDF) is well conserved across species and is the smallest form that retains the full range of biological actions ${ }^{2}$, mediated by two $C C K$ receptor subtypes $\left(\mathrm{CCK}_{\mathrm{A}} \mathrm{R}\right.$ and $\left.\mathrm{CCK}_{\mathrm{B}} \mathrm{R}\right)$, which are present throughout the $\mathrm{CNS}$ and the gut. $\mathrm{CCK}_{\mathrm{A}} \mathrm{R}$ is primarily expressed in the alimentary tract, while $\mathrm{CCK}_{\mathrm{B}} \mathrm{R}$ is mainly found in the brain and the stomach ${ }^{3}$. $\mathrm{CCK}_{\mathrm{A}} \mathrm{R}$ has a $\sim 500$-fold higher affinity to $\mathrm{CCK}$ that has a sulfated tyrosine, whereas $\mathrm{CCK}_{\mathrm{B}} \mathrm{R}$ discriminates poorly between sulfated and non-sulfated $\mathrm{CCK}^{4}$.

$\mathrm{CCK}$ regulates appetite and food intake primarily through $\mathrm{CCK}_{\mathrm{A}} \mathrm{R}$ on the vagal afferent neurons ${ }^{5-8}$, making $\mathrm{CCK}_{\mathrm{A}} \mathrm{R}$ an attractive therapeutic target for obesity. However, drug development against $\mathrm{CCK}_{\mathrm{A}} \mathrm{R}$ is challenging, partly due to limited efficacy and safety concerns. Although several 30 drug candidates are undergoing clinical trials, none has been approved to date ${ }^{9,10}$. Extensive efforts were made to elucidate the mechanism of agonism at $\mathrm{CCK}_{\mathrm{A}} \mathrm{R}$ through mutagenesis studies based on modeled receptor structures ${ }^{11-15}$. Nonetheless, the lack of precise structural information largely impedes our understanding of the molecular details regarding ligand recognition and receptor activation, thus the drug discovery targeting $\mathrm{CCK}_{\mathrm{A}} \mathrm{R}$.

Most G protein-coupled receptors (GPCRs) are known to couple with a specific subtype of G proteins to elicit intracellular signal transduction ${ }^{16-23}$. There are four $\mathrm{G}$ protein subtypes, i.e., stimulatory $G$ protein $\left(G_{s}\right)$, inhibitory $G$ proteins $\left(G_{i}\right), G_{q}$, and $G_{12 / 13}$, participating in signaling pathways involving cAMP $\left(\mathrm{G}_{\mathrm{s}}\right.$ and $\left.\mathrm{G}_{\mathrm{i}}\right)$, calcium $\left(\mathrm{G}_{\mathrm{q}}\right)$, and small $\mathrm{G}$ protein $\left(\mathrm{G}_{12 / 13}\right)$. A number of GPCR-G protein complex structures reported recently reveal that the primary determinants of $G$ 
protein coupling selectivity reside in the C-terminal $\alpha 5$ helix of $\mathrm{G} \alpha$ subunit and relative outward movement of TM6 ${ }^{24,25}$. However, $\mathrm{CCK}_{\mathrm{A}} \mathrm{R}$ is different from most GPCRs for its ability to couple with several subtypes of $\mathrm{G}$ proteins. Activation of $\mathrm{CCK}_{\mathrm{A}} \mathrm{R}$ elicits a diversified $\mathrm{G}$ protein coupling pattern ${ }^{26}$ : predominantly $\mathrm{G}_{\mathrm{q}}{ }^{27}$, but $\mathrm{G}_{\mathrm{s}}{ }^{28}, \mathrm{G}_{\mathrm{i}}{ }^{27,29}$, and $\mathrm{G}_{13}{ }^{30,31}$ all play their roles in $\mathrm{CCK}_{\mathrm{A}} \mathrm{R}$ signaling. This unique feature makes $\mathrm{CCK}_{\mathrm{A}} \mathrm{R}$ an ideal model to study $\mathrm{G}$ protein selectivity and promiscuity (Fig. 1a). Here, we report three cryo-EM structures of sulfated CCK-8 activated $\mathrm{CCK}_{\mathrm{A}} \mathrm{R}$ in complex with heterotrimeric $G_{q}, G_{s}$, or $G_{i}$ protein, respectively. These structures reveal the unique binding mode in ligand recognition and the structural determinants responsible for $\mathrm{G}$ protein selectivity and promiscuity of $\mathrm{CCK}_{\mathrm{A}} \mathrm{R}$.

\section{Overall structures of $\mathrm{CCK}_{\mathbf{A}} \mathrm{R}$ coupled to different $\mathrm{G}$ proteins}

The structures of sulfated CCK-8 bound $\mathrm{CCK}_{\mathrm{A}} \mathrm{R}$ in complex with $\mathrm{G}_{\mathrm{q}}, \mathrm{G}_{\mathrm{s}}$, or $\mathrm{G}_{\mathrm{i}}$ heterotrimers were determined by single-particle cryo-EM at a global resolution of $2.9 \AA, 3.1 \AA$, and $3.2 \AA$, respectively (Fig. 1, Extended Data Fig. 1, Extended Data Table 1). Sulfated CCK-8 (DY ${ }^{\mathrm{SO} H}{ }_{\mathrm{MGMWDF}-\mathrm{NH}_{2}}$ ), the highest affinity natural ligand of $\mathrm{CCK}_{\mathrm{A}} \mathrm{R}^{4}$, was used to assemble the $\mathrm{CCK}_{\mathrm{A}} \mathrm{R}-\mathrm{G}$ protein complexes. Three $\mathrm{G}$ protein subtypes were engineered to stabilize the $\mathrm{CCK}_{\mathrm{A}} \mathrm{R}-\mathrm{G}$ protein complexes (Extended Data Fig. 2). $G \alpha_{q}$ is chimerized by replacing its $\alpha \mathrm{N}$ helix with the equivalent region of $\mathrm{G} \alpha_{i 1}$ to facilitate $\mathrm{scFv} 16$ binding ${ }^{32}$. $\mathrm{G} \alpha_{\mathrm{s}}$ was modified based on mini-G $\alpha_{\mathrm{s}}$ that was used in the crystal structure determination of the $\mathrm{G}_{\mathrm{s}}$-coupled adenosine $\mathrm{A}_{2 \mathrm{~A}}$ receptor $\left(\mathrm{A}_{2 \mathrm{~A}} \mathrm{R}\right)^{33}$. Two dominant-negative (DN) mutations (G203A and $\mathrm{A} 326 \mathrm{~S}^{34}$ ) were introduced to $\mathrm{G} \alpha_{\mathrm{il}}$, and corresponding DN mutations at equivalent sites of $\mathrm{G} \alpha_{\mathrm{s}}$ and $\mathrm{G} \alpha_{\mathrm{q}}$ were also introduced (Extended Data Fig. 2b). Unless otherwise specified, $G_{q}, G_{s}$, and $G_{i}$ refer to respective engineered $G$ proteins, which are used in $C_{C K} R$ structure determination.

The final structures of the CCK- $8-\mathrm{CCK}_{\mathrm{A}} \mathrm{R}-\mathrm{G}$ protein complexes contain sulfated CCK-8

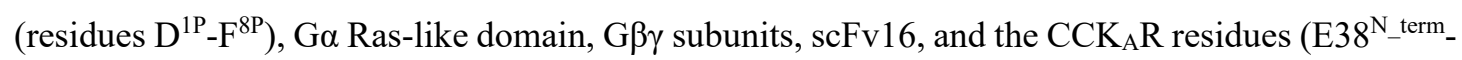
F $385^{8.58}$, superscripts refer to Ballesteros-Weinstein numbering ${ }^{35}$ ). The majority of amino acid side chains, including CCK-8, transmembrane domain (TMD), intracellular loops (ICLs 1-3), and extracellular loops (ECLs 1-3) were well resolved in the final models (Extended Data Fig. 3). Thus, the complex structures provide reliable details to study mechanisms of ligand recognition and $\mathrm{G}$ protein coupling.

Globally, $\mathrm{CCK}_{\mathrm{A}} \mathrm{R}$ adopts similar overall conformations in all the three structures, with the allatom root-mean-square deviation (RMSD) at 0.84 for $\mathrm{G}_{\mathrm{q}} / \mathrm{G}_{\mathrm{s}}$-coupled receptors, and 1.03 for $\mathrm{G}_{\mathrm{q}} / \mathrm{G}_{\mathrm{i}^{-}}$ coupled receptors. The structure of the CCK-8- $\mathrm{CCK}_{\mathrm{A}} \mathrm{R}-\mathrm{G}_{\mathrm{q}}$ complex, which has the highest resolution at $2.9 \AA$, was used for detailed analysis and mechanistic evaluation of ligand recognition and receptor activation. The inactive and active structures of the closed homolog receptors (inactive: ghrelin receptor, PDB: $6 \mathrm{KO}^{36}{ }^{36}$; active: neurotensin receptor 1, NTSR1, PDB: 6 OS9 ${ }^{19}$ ), all belong to the $\beta$-branch of the rhodopsin family, are applied for structural comparison. $\mathrm{CCK}_{\mathrm{A}} \mathrm{R}$ presents a fully active conformation, resembling the $\mathrm{G}_{\mathrm{i}}$-coupled NTSR1, displaying a $\sim 9 \AA$ outward movement 
of TM6 (measured at $\mathrm{C} \alpha$ of residue at position 6.27 in $\mathrm{CCK}_{\mathrm{A}} \mathrm{R}$ and ghrelin receptor) and $\sim 4 \AA$ inward shift of TM7 ( $\mathrm{C} \alpha$ carbons of Y7.53) compared with the inactive ghrelin receptor (Extended Data Fig. 4, a and b). Similar to the active NTSR1 complex, the conserved residues in "microswitches" (PIF, ERY, CWxP, and NPxxY) of $\mathrm{CCK}_{\mathrm{A}} \mathrm{R}$ display the conserved conformations observed in active GPCRs (Extended Data Fig. 4c).

\section{Recognition of sulfated cholecystokinin}

85 The sulfated CCK-8 occupies the orthosteric binding pocket comprised of TM3, TM4, TM5-7, and ECL1-3 (Fig. 2, Extended Data Figs. 5, 6), with its C-terminus inserting into the TMD bundle and the N-terminus facing the extracellular vestibule (Fig. 2a). The binding pocket of CCK-8 is largely overlapped with that of other reported endogenous neuropeptides, such as neurotensin $\left(\mathrm{NTS}_{8-13}\right.$, PDB: $6 \mathrm{OS} 9{ }^{19}$ ), angiotensin II (Ang II, PDB: $6 \mathrm{OS} 0^{37}$ ), orexin B (OXB, PDB: 7L1U ${ }^{38}$ ), and arginine vasopressin (AVP, PDB: 7DW9 ${ }^{39}$ ). Noteworthily, the extracellular side of these neuropeptides undergo remarkable conformational shifts, while their intracellular parts converge in an approximately overlapped position at the bottom of the binding pocket (Extended Data Fig. 7).

Of interest is that the octapeptide CCK- 8 almost completely occupies the polypeptide-binding pocket, structurally supporting the fact that it is the smallest active form of CCK isoforms. The binding modes of CCK- 8 are highly conserved in all three $\mathrm{CCK}_{\mathrm{A}} \mathrm{R}-\mathrm{G}$ protein complexes (all-atom RMSD 0.71 for CCK-8 in $\mathrm{G}_{\mathrm{q}} / \mathrm{G}_{\mathrm{s}}$-coupled complexes, and 1.18 for CCK-8 in $\mathrm{G}_{\mathrm{q}} / \mathrm{G}_{\mathrm{i}}$-coupled complexes), supported by clear EM density maps (Fig. 2a, Extended Data Fig. 3). The ligand recognition region by $\mathrm{CCK}_{\mathrm{A}} \mathrm{R}$ can be divided into three major parts: (i) the extracellular loops, (ii) hydrophobic cavities beneath ECLs, and (ii) the bottom of the TMD pocket (Fig. 2a).

At the extracellular side, three ECLs are folded to embrace the N-terminal amino acids of CCK8 (Fig. 2a). The sulfate group of $\mathrm{Y}^{2 \mathrm{P}}$ ionic interacts with the side chain of R197 ${ }^{\mathrm{ECL} 2}$. This polar interaction prompts the aromatic ring of $\mathrm{Y}^{2 \mathrm{P}}$ to form hydrophobic contacts with $\mathrm{F} 185^{\mathrm{ECL} 2}$, M195 ${ }^{\mathrm{ECL} 2}$, and the main chain of K105 ${ }^{\mathrm{ECL} 1}$, thus connecting CCK-8 to ECL1 and ECL2 (Fig. 2b, Extended Data Fig. 6). These structural observations are consistent with the previous finding that the $\mathrm{R} 197^{\mathrm{ECL} 2} \mathrm{M}$ mutation was 1,470 -fold less potent than the wild-type (WT) $\mathrm{CCK}_{\mathrm{A}} \mathrm{R}^{11}$. The alanine mutation of R197 ${ }^{\mathrm{ECL} 2}$ completely abolishes the binding of CCK-8, thus strongly supporting the contention that R197 ${ }^{\mathrm{ECL} 2}$ serves as a determinant to discriminate between sulfated and nonsulfated CCK (Fig. 2f, Extended Data Table 2). Likewise, poor ligand selectivity of $\mathrm{CCK}_{\mathrm{B}} \mathrm{R}$ may be attributed to a substitution of arginine for valine at the corresponding position (Extended Data Fig. 5). Meanwhile, $M^{3 P}, G^{4 P}$, and $W^{5 P}$ clamp the interior surface of ECL3 (Fig. 2b).

Two hydrophobic cavities exist below the ECLs to accommodate $\mathrm{M}^{5 \mathrm{P}}$ and $\mathrm{W}^{6 \mathrm{P}}$ (Fig. 2c, d). The side chain of $\mathrm{W}^{5 \mathrm{P}}$ is sandwiched by the side chains of $\mathrm{I} 352^{7.35}$ and $\mathrm{R} 336^{6.58}$ and buries in a deep hydrophobic pocket comprised of TM6, ECL3, and TM7 (Fig. 2c). The backbone CO group of $\mathrm{W}^{5 \mathrm{P}}$ forms an H-bond with R336 6.58 , and its indole nitrogen atom makes another H-bond with N333 3.55 
mutations in residues $\mathrm{N} 333^{6.55}, \mathrm{R} 336^{6.58}, \mathrm{~A} 343^{\mathrm{ECL} 3}$, E344 ${ }^{\mathrm{ECL} 3}, \mathrm{~L} 347^{\mathrm{ECL} 3}$, and S348 ${ }^{\mathrm{ECL} 3}$ completely abolish the binding of CCK-8, suggesting the key roles of these residues in CCK-8 recognition (Fig. 2f, Extended Data Table 2). In contrast to the $\mathrm{W}^{5 \mathrm{P}}$-occupied hydrophobic pocket, $\mathrm{M}^{6 \mathrm{P}}$ sits in a relatively shallow hydrophobic cavity in the opposite direction, constituted by F107 ${ }^{\mathrm{ECL}}$, C196 ${ }^{\mathrm{ECL} 2}$, T118 ${ }^{3.29}$, and M121 $1^{3.32}$ (Fig. 2d, Extended Data Fig. 6). Mutating F107 ${ }^{\mathrm{ECL} 1}$ and residues in ECL2 and ECL3 to alanine eliminated the binding ability of CCK-8 entirely, highlighting an essential function of the three ECLs in peptide recognition (Fig. 2f, Extended Data Table 2).

At the bottom of the binding pocket, $\mathrm{D}^{7 \mathrm{P}}$ and main chain $\mathrm{CO}$ group of CCK- 8 form a stabilizing polar interaction network with TM5 (H210 $\left.{ }^{5.39}\right)$, TM6 (N333 $3^{6.55}$ and R336 ${ }^{6.58}$ ), and TM7 (Y360 ${ }^{7.43}$ ) (Fig. 2e, Extended Data Fig. 6). The phenyl ring of $\mathrm{F}^{8 \mathrm{P}}$ makes polar hydrogen-pi interaction with Y176 $6^{4.60}$, and inserts into a large hydrophobic crevice comprised of residues from TM3, TM4, TM5, and TM6 (Fig. 2e, Extended Data Fig. 6). Besides N333 $3^{6.55}$ and R336 6.58 , which also polar interact with $\mathrm{W}^{5 \mathrm{P}}, \mathrm{I} 329^{6.51}$ is closely related to CCK-8 binding (Fig. 2f, Extended Data Table 2).

Elucidation of the recognition mechanism of CCK-8 provides clues for therapeutic development against $\mathrm{CCK}_{\mathrm{A}} \mathrm{R}$. GW-5823, CE-326597, and Glaxo-11p are small molecule agonists for $\mathrm{CCK}_{\mathrm{A}} \mathrm{R}$ with moderate activities ${ }^{10,41,42}$. Docking of these agonists to the $\mathrm{CCK}_{\mathrm{A}} \mathrm{R}$ shows that they only occupy the bottom half of the TMD binding pocket, thus lacking essential interactions with ECLs1-3 of $\mathrm{CCK}_{\mathrm{A}} \mathrm{R}$ (Extended Data Fig. 8). This structural feature may lead to a weaker activity of these small molecule agonists relative to CCK-8. Together, our data provide a framework for understanding the mechanism of small molecule agonist recognition and offer a template for guiding drug design targeting $\mathrm{CCK}_{\mathrm{A}} \mathrm{R}$.

\section{Overall coupling mode of $\mathrm{CCK}_{\mathbf{A}} \mathrm{R}-\mathrm{G}$ protein complexes}

Although all the four $\mathrm{G}$ protein subtypes were reported to interact with $\mathrm{CCK}_{\mathrm{A}} \mathrm{R}^{26}$, only three of the $\mathrm{CCK}_{\mathrm{A}} \mathrm{R}-\mathrm{G}$ protein samples $\left(\mathrm{CCK}_{\mathrm{A}} \mathrm{R}-\mathrm{G}_{\mathrm{q}}, \mathrm{CCK}_{\mathrm{A}} \mathrm{R}-\mathrm{G}_{\mathrm{s}}\right.$, and $\mathrm{CCK}_{\mathrm{A}} \mathrm{R}-\mathrm{G}_{i}$ protein complexes) were obtained for high-resolution cryo-EM structure determination (Fig. 1). Structural comparison indicated that TM6 and ICL2 in $\mathrm{CCK}_{\mathrm{A}} \mathrm{R}$ adopt nearly identical conformations in $\mathrm{G}_{\mathrm{q}^{-}}, \mathrm{G}_{\mathrm{i}^{-}}$, and $\mathrm{G}_{\mathrm{s}^{-}}$ coupled structures (Fig. 3a, Extended Data Fig. 7). However, slightly different tilts of the G $\alpha$ a5 helix were seen among the three heterotrimeric $G$ proteins $\left(4^{\circ}\right.$ for $\mathrm{G} \alpha_{q} / G \alpha_{s}$ and $8^{\circ}$ for $\left.G \alpha_{q} / G \alpha_{i}\right)(F i g$. 3a). Meanwhile, the distal end of $\mathrm{G} \alpha_{\mathrm{s}} \alpha 5$ helix moves $7 \AA$ outward away from the TMD core relative to the equivalent $\mathrm{G} \alpha_{\mathrm{q}}$ residue (measured at $\mathrm{C} \alpha$ atom of $\mathrm{L}^{\mathrm{H} 5.25}$, superscript refers to CGN system ${ }^{43}$ ) (Fig. 3a). The $\mathrm{G}_{\mathrm{q}}$ presents the largest solvent-accessible surface area (SASA, $1492 \AA^{2}$ ) with the receptor compared to $\mathrm{G}_{\mathrm{s}}\left(1293 \AA^{2}\right)$ and $\mathrm{G}_{\mathrm{i}}\left(1167 \AA^{2}\right)$, consistent with a 6.6- to 20.3-fold increased potency of $\mathrm{G}_{\mathrm{q}}$ coupling to $\mathrm{CCK}_{\mathrm{A}} \mathrm{R}$ in comparison to that coupled with $\mathrm{G}_{\mathrm{s}}$ and $\mathrm{G}_{\mathrm{i}}$ (Extended Data Fig.

Table 3). This finding supports the hypothesis that the size of the $G$ protein coupling interface may correlate with the ability of a receptor to link with different $\mathrm{G}$ proteins ${ }^{23,24}$. In addition, coupling of different $G$ protein subtypes exhibits distinct effects on CCK-8 binding. Compared to $G_{s}$ or $G_{i}$ proteins, $G_{q}$ coupling increases the binding affinity of CCK-8 (Extended Data Table 3), consistent 
with the increased binding activity of isoproterenol against $\beta_{2 A} R$ in the presence of $G_{s}$ protein ${ }^{16}$.

This finding indicates an allosteric modulation effect of $\mathrm{G}_{\mathrm{q}}$ protein on CCK-8 binding, supporting the positive cooperativity between agonists and $\mathrm{G}$ proteins ${ }^{44}$.

In addition, comparisons of these three complex structures to previously reported $G$ proteincoupled class A GPCRs reveal the different extent of TM6 displacement and concomitant shift of $\mathrm{G} \alpha \alpha 5$ helix (Fig. 3b-d). TM6 of $\mathrm{CCK}_{\mathrm{A}} \mathrm{R}$ in all three G protein complexes displays an 11-12 (measured at $\mathrm{C} \alpha$ atom of residue at position 6.27) smaller outward displacement in contrast to $\mathrm{G}_{\mathrm{s}^{-}}$ coupled GPCRs, which translates into a notable swing of $\mathrm{G} \alpha \alpha 5$ helix in the same direction (9-11 relative to $\mathrm{G}_{\mathrm{s}}$-coupled $\beta_{2 \mathrm{~A}} \mathrm{R}$ and $\mathrm{A}_{2 \mathrm{~A}} \mathrm{R}$ as measured at $\mathrm{C} \alpha$ atom of $\mathrm{Y}^{\mathrm{H5} 5.23}$ ). This smaller displacement of TM6 is contrary to the previous assumption that TM6 of Gs-coupled GPCRs undergoes a significant outward movement, thus opening a larger cytoplasmic pocket to accommodate bulkier residues at the distal end of $\mathrm{G} \alpha_{\mathrm{s}} \alpha 5$ helix relative to $\mathrm{G}_{\mathrm{i} / \mathrm{o}^{-}}$coupled receptors ${ }^{23,45}$. To avoid a potential clash with TM6, the distal end of the $\mathrm{G} \alpha_{\mathrm{S}} \alpha 5$ helix in the $\mathrm{CCK}_{\mathrm{A}} \mathrm{R}-\mathrm{G}_{\mathrm{s}}$ complex stretches away from the TMD core and inserts into the crevice between TM6 and TM7-helix 8 joint. This featured conformation of $\mathrm{G} \alpha_{\mathrm{S}} \alpha 5$ helix in the $\mathrm{CCK}_{\mathrm{A}} \mathrm{R}-\mathrm{G}_{\mathrm{s}}$ complex is unique compared to that in structures of the $G_{s}$-coupled $\beta_{2 A} R$ and $A_{2 A} R$, supporting the complexity of GPCR-G protein coupling mechanism (Fig. 3b).

TM6 and $\mathrm{G} \alpha \alpha 5$ helix of $\mathrm{CCK}_{\mathrm{A}} \mathrm{R}-\mathrm{G}$ protein complexes display similar conformational changes to other $\mathrm{G}_{\mathrm{i}}$ - and $\mathrm{G}_{\mathrm{q}}$-coupled GPCRs, such as the $\mathrm{G}_{\mathrm{i}}$-coupled NTSR1 and the $\mathrm{G}_{\mathrm{q}^{-}}$-coupled 5- $\mathrm{HT}_{2 \mathrm{~A}} \mathrm{R}$ (Fig. 3c, d). TM6 of $\mathrm{CCK}_{\mathrm{A}} \mathrm{R}-\mathrm{G}_{\mathrm{i}}$ protein complex is highly overlaid with that of $\mathrm{G}_{\mathrm{i}}$-coupled NTSR1, while the cytoplasmic end of TM6 shows a $4 \AA$ smaller outward displacement compared to that of

$175 \mathrm{G}_{0}$-coupled $\mathrm{M}_{2} \mathrm{R}$ (Fig. 3c). On the $\mathrm{G}$ protein side, the $\alpha 5$ helix of $G \alpha_{i}$ in the $C C K_{A} R-G_{i}$ complex shows a nearly overlapped conformation compared to that of the NTSR $1-\mathrm{G}_{\mathrm{i}}$ complex. In contrast, it exhibits a $3 \AA$ (measured at $\mathrm{C} \alpha$ atom of $\mathrm{Y}^{\mathrm{H} 5.23}$ ) shift away from TM6 relative to that of $\mathrm{G}_{0}$-coupled $\mathrm{M}_{2} \mathrm{R}$ (Fig. 3c). Structural comparison of $\mathrm{G}_{\mathrm{q}}$-coupled $\mathrm{CCK}_{\mathrm{A}} \mathrm{R}$ with $\mathrm{G}_{\mathrm{q}} / \mathrm{G}_{11}$-coupled GPCRs demonstrates a $2 \AA$ (measured at $\mathrm{C} \alpha$ atom of $\mathrm{Y}^{\mathrm{H} 5.23}$ ) upward toward the cytoplasmic cavity in contrast to the $\mathrm{G}_{\mathrm{q}}$-coupled 5- $\mathrm{HT}_{2 \mathrm{~A}} \mathrm{R}$ and a $28^{\circ}$ rotation away from TM6 relative to $\mathrm{G}_{11}$-coupled $\mathrm{M}_{1} \mathrm{R}$ (Fig. 3d).

\section{Interaction patterns for the "wavy hook" of the $\mathrm{CCK}_{\mathrm{A}} \mathrm{R}-\mathrm{G}$ protein complexes}

The "wavy hook" at the extreme C-terminus of the G $\alpha \alpha 5$ helix is thought to be one of the coupling specificity determinants for $\mathrm{G}$ protein ${ }^{46,47}$, which undergoes distinct conformational rearrangements among the three $\mathrm{CCK}_{\mathrm{A}} \mathrm{R}-\mathrm{G}$ protein complexes (Fig. 3a).

A structural comparison of the interaction interface between the receptor cytoplasmic cavity and $\mathrm{G} \alpha$ "wavy hook" reveals distinct features of $\mathrm{CCK}_{\mathrm{A}} \mathrm{R}-\mathrm{G}$ protein coupling. Well-defined densities of $\mathrm{G} \alpha$ protein "wavy hook" residues allow for detailed structural analyses except for residues at the -1 position. $\mathrm{L}(-2)^{\mathrm{H} 5.25}$ in $\alpha 5$ helix is highly conserved across the $\mathrm{G}$ protein families and plays a pivotal role in $\mathrm{G}$ protein coupling. Both $\mathrm{L} 358^{\mathrm{H} 5.25}$ in $\mathrm{G} \alpha_{\mathrm{q}}$ and $\mathrm{L} 353^{\mathrm{H} 5.25}$ in $\mathrm{G} \alpha_{\mathrm{i}}$ hydrophobically 
interact with residues in TM3 and TM6 (R139 ${ }^{3.50}, \mathrm{I}_{143^{3.54}}$, V311 ${ }^{6.33}$, and L315 $5^{6.37}$ ) (Fig. 4a, b). Due to the notable displacement of $\mathrm{G} \alpha_{\mathrm{s}} \mathrm{C}$-terminus, $\mathrm{L} 393^{\mathrm{H} 5.25}$ in $\mathrm{G} \alpha_{\mathrm{s}}$ moves $7 \AA$ ̊utward away from the TMD core relative to the equivalent $\mathrm{G} \alpha_{\mathrm{q}}$ residue (Fig. 3a), repositioning it in a hydrophobic subpocket formed by M314 $4^{6.36}$ and M373 $3^{7.56}$ (Fig. 4c). In contrast to $\mathrm{L}(-2)^{\mathrm{H} 5.25}$, residues at positions $\mathrm{H}(-$ $3)^{5.24}, \mathrm{H}(-4)^{5.23}$ and $\mathrm{H}(-5)^{5.22}$ are less conserved. N357(-3) ${ }^{\mathrm{H} 5.24}$ in $\mathrm{G} \alpha_{\mathrm{q}}$ makes an H-bond with the backbone CO group of $\mathrm{Y}_{370^{7.53}}$ (Fig. 4a). Owing to the replacement of $\mathrm{G} \alpha_{\mathrm{i}} \mathrm{G} 352(-3)^{\mathrm{H} 5.24}$ and the reposition of $\mathrm{G} \alpha_{\mathrm{s}} \mathrm{E} 392(-3)^{\mathrm{H} 5.24}$, the corresponding H-bond is absent in $\mathrm{CCK}_{\mathrm{A}} \mathrm{R}-\mathrm{G}_{\mathrm{i}}$ and $\mathrm{CCK}_{\mathrm{A}} \mathrm{R}-\mathrm{G}_{\mathrm{s}}$ complex structures. Additionally, $\mathrm{Y} 356(-4)^{\mathrm{H} 5.23}$ in $\mathrm{G} \alpha_{\mathrm{q}}$ forms extensive interactions with the receptor cytoplasmic cavity by making H-bonds with R139.350 and Q153 ${ }^{\text {ICL2 }}$ (Fig. 4d). In contrast, C351($4)^{\mathrm{H} 5.23}$ in $\mathrm{Gd}_{\mathrm{i}}$ only forms a weak H-bond with R139.50 via its backbone CO group (Fig. 4e). Y391($4)^{\mathrm{H} 5.23}$ in $\mathrm{G} \alpha_{\mathrm{s}}$ exhibits limited hydrophobic and Van der Waals interactions with residues in TM2 and TM3 (T76 ${ }^{2.39}$, R139 $9^{3.50}$, and A142 $2^{3.53}$ ) (Fig. 4f). Furthermore, both E355(-5) ${ }^{\mathrm{H} 5.22}$ in $\mathrm{G} \alpha_{\mathrm{q}}$ and $\mathrm{D} 350(-5)^{\mathrm{H} 5.22}$ in $\mathrm{G} \alpha_{\mathrm{i}}$ form salt bridges with $\mathrm{R} 376^{8.49}$ in $\mathrm{CCK}_{\mathrm{A}} \mathrm{R}$, while Q390(-5) ${ }^{\mathrm{H} 5.22}$ in $\mathrm{G} \alpha_{\mathrm{S}}$ disfavors the formation of corresponding electrostatic interaction (Fig. 4d-f). To understand the "wavy hook" mediated G-protein selectivity, we displaced the amino acids (H5.22-H5.25) in $\mathrm{G \alpha}_{\mathrm{q}}$ subunit with the corresponding ones in $G \alpha_{s}$ and $G \alpha_{i}$ subunits. BRET assay results show that the $G \alpha_{i}$ displacement has no impact on $\mathrm{CCK}_{\mathrm{A}} \mathrm{R}-\mathrm{G}$ protein coupling compared to wild-type $\mathrm{G} \alpha_{q}$ subunit. However, partially (E355Q or N357E) or completely $\mathrm{G}_{\mathrm{s}}$ substitution remarkably decreased the G protein coupling activity of $\mathrm{CCK}_{\mathrm{A}} \mathrm{R}$ (Fig. $4 \mathrm{~g}$ ). These results indicate that the "wavy hook" may play a crucial role in coupling selectivity of $\mathrm{CCK}_{\mathrm{A}} \mathrm{R}$ with $\mathrm{G}_{\mathrm{q}}$ over $\mathrm{G}_{\mathrm{s}}$ protein.

\section{Contribution of $\mathrm{CCK}_{\mathrm{A}} \mathrm{R}$ ICL3 to $\mathrm{G}_{\mathbf{q}}$-coupling selectivity}

In the $\mathrm{CCK}_{\mathrm{A}} \mathrm{R}-\mathrm{G}_{\mathrm{q}}$ protein complex structure, $\mathrm{CCK}_{\mathrm{A}} \mathrm{R}$ displays a comparable length of TM5 relative to $\mathrm{M}_{1} \mathrm{R}-\mathrm{G}_{11}$ complex ${ }^{21}$. However, the cytoplasmic end of $\mathrm{CCK}_{\mathrm{A}} \mathrm{R}$ TM5 exhibits an $8 \AA$ outward bend (measured at $\mathrm{C} \alpha$ atoms of $\mathrm{A}^{5.73}$ ), which prevents it from interacting with the $\mathrm{G} \alpha_{\mathrm{q}}$ subunit (Fig. 5a). Instead, the ICL3 inserts into the cleft between TM5 of CCK $\mathrm{A}$ and $\alpha 5$ helix of the $\mathrm{G} \alpha_{q}$ subunit (Fig. 5a). Compared to $\mathrm{L} 225^{5.75}$ in $\mathrm{M}_{1} \mathrm{R}, \mathrm{I}_{2} 96^{\mathrm{ICL} 3}$ in $\mathrm{CCK}_{\mathrm{A}} \mathrm{R}$ interacts with the same hydrophobic patch formed by side chains of $\mathrm{Y} 325^{\mathrm{S} 6.02}, \mathrm{~F} 339^{\mathrm{H} 5.06}$, and $\mathrm{A} 342^{\mathrm{H} 5.09}$ in $\mathrm{G} \alpha_{\mathrm{q}}$ subunit, but is buried deeper to create more closely packed hydrophobic contacts (Fig. 5a, b). These hydrophobic interactions are critical to $\mathrm{CCK}_{\mathrm{A}} \mathrm{R}-\mathrm{G}_{\mathrm{q}}$ coupling, as evidenced by our BRET analysis that $\mathrm{I} 296^{\mathrm{ICL} 3} \mathrm{G}$ mutation significantly weakened $G_{q}$ coupling to $\mathrm{CCK}_{\mathrm{A}} \mathrm{R}$ but had no impact on $\mathrm{G}_{\mathrm{s}}$ and $\mathrm{G}_{\mathrm{i}}$ coupling (Fig. 5c, Extended Data Table 4). This hydrophobic patch that lies on the outer surface may be unique for the $\mathrm{G}_{\mathrm{q} / 11}$ subunit. The equivalent residues in $\mathrm{G} \alpha_{\mathrm{s}}$ and $\mathrm{G} \alpha_{\mathrm{i}}$ subunits are polar or charged residues, which would be energetically unfavorable to form hydrophobic interactions (Extended Data Fig. 10). Indeed, this unconventional ICL3- $\mathrm{G}_{\mathrm{q}}$ interaction is not seen in the structures of $\mathrm{G}_{\mathrm{s}^{-}}$ and $\mathrm{G}_{\mathrm{i} / \mathrm{o}}$-coupled $\mathrm{CCK}_{\mathrm{A}} \mathrm{Rs}$ (Fig. 3b, c). Together, our findings offer structural evidence on the possible role of ICL3 in $\mathrm{CCK}_{\mathrm{A}} \mathrm{R}-\mathrm{G}_{\mathrm{q}}$ coupling preference. Hydrophobic residues on the inner surface of the ICL3 loop of $\mathrm{CCK}_{\mathrm{A}} \mathrm{R}$ or the extended TM5 of $\mathrm{M}_{1} \mathrm{R}$ may represent a common feature of $\mathrm{G}_{\mathrm{q} / 11^{-}}$ 
coupled GPCRs.

\section{Conclusions}

As the largest family of cell surface receptors, GPCRs have more than 800 members but only couple to four G protein subtypes. Specific GPCR signaling requires the receptor to couple with either a single or multiple $\mathrm{G}$ protein subtypes ${ }^{47-49}$. Thus, one of the main questions is how does a given GPCR select a $G$ protein subtype for downstream signal transduction. The critical $G$ protein determinants of selectivity vary widely for different receptors that couple to specific G proteins. It is thought that $\mathrm{G}_{\mathrm{s}}-$ or $\mathrm{G}_{\mathrm{q}}$-coupled receptors are relatively promiscuous and to some extent couple to $\mathrm{G}_{\mathrm{i} 1}{ }^{24}$. However, $\mathrm{G}_{\mathrm{i}}$-coupled receptors are more selective ${ }^{24}$. The minor outward movement of TM6 contributes to such a superior $\mathrm{G}_{\mathrm{i}}$-coupling selection as opposed to that of $\mathrm{G}_{\mathrm{s}}{ }^{18,25,46,50,51}$. Although proven to be promiscuous, $\mathrm{G}_{\mathrm{q}}$-coupled receptors tend to adopt an active conformation similar to that of $\mathrm{G}_{\mathrm{i}}$-coupled GPCRs, reflecting the complexity of the GPCR-G protein coupling mechanism ${ }^{21,22}$. Since $\mathrm{CCK}_{\mathrm{A}} \mathrm{R}$ has the ability to couple with different $\mathrm{G}$ protein subtypes, it stands out as a suitable model for studying the promiscuity of $G$ protein coupling. In this paper, we show that TM6 of $\mathrm{CCK}_{\mathrm{A}} \mathrm{R}$ undergoes a similar outward displacement relative to $\mathrm{G}_{\mathrm{i} / \mathrm{o}}$-coupled (NTSR1 and $\mathrm{M}_{2} \mathrm{R}$ ) and

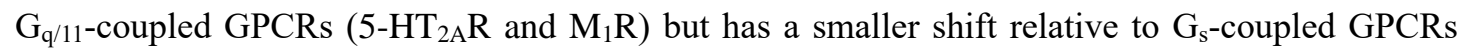
$\left(\beta_{2 \mathrm{~A}} R\right.$ and $\left.A_{2 A} R\right)$. $C C K_{A} R s$ share almost identical conformations, whereas $G_{q}, G_{s}$, and $G_{i}$ proteins vary in distinct orientations, producing different sizes of receptor-G protein interface. The predominant coupling to $\mathrm{G}_{\mathrm{q}}$ by $\mathrm{CCK}_{\mathrm{A}} \mathrm{R}$ can be explained by the largest interface among three $\mathrm{CCK}_{\mathrm{A}} \mathrm{R}-\mathrm{G}$ protein complexes. Structural comparison of the three $\mathrm{CCK}_{\mathrm{A}} \mathrm{R}-\mathrm{G}$ protein complexes reveals that "wavy hook" residues of G $\alpha \alpha 5$ helix and ICL3 of the receptor are important for the coupling promiscuity. In addition, detailed inspections disclose structural clues relative to the recognition mechanism of sulfated CCK-8 by $\mathrm{CCK}_{\mathrm{A}} \mathrm{R}$, in which $\mathrm{R} 197^{\mathrm{ECL} 2}$ is a major determinant. Together, our structures provide a framework for better understanding of ligand recognition as well as $\mathrm{G}$ protein coupling selectivity and promiscuity by $\mathrm{CCK}_{\mathrm{A}} \mathrm{R}$.

\section{Methods}

\section{Expression and purification of $\mathrm{CCK}_{\mathbf{A}} \mathrm{R}-\mathrm{G}$ protein complexes}

The WT $\mathrm{CCK}_{\mathrm{A}} \mathrm{R}$ (residues 1-428) was applied for cryo-EM studies. The full-length $\mathrm{CCK}_{\mathrm{A}} \mathrm{R}$ cDNA was cloned into a modified pFastBac vector (Invitrogen) containing a hemagglutinin (HA) signal sequence followed by an $8 \times$ histidine tag, a double-MBP tag, and a TEV protease site before the receptor sequence using homologous recombination (CloneExpress One Step Cloning Kit, Vazyme) (Extended Data Fig. 2a). The N-terminal 1-29 amino acids of $G \alpha_{q}$ was replaced by the equivalent residues of $\mathrm{G}_{\mathrm{i} 1}$ to facilitate the scFv16 binding ${ }^{21}$. An engineered $\mathrm{G} \alpha_{\mathrm{s}}$ construct was generated based on mini-G $\alpha_{s}{ }^{33}$. The N-terminal 1-18 amino acids and $\alpha$-helical domain of $G \alpha_{s}$ were replaced by human $\mathrm{G} \alpha_{i 1}$, thus providing binding sites for scFv16 and Fab-G50, respectively ${ }^{18,21}$. Additionally, human $\mathrm{G}_{\mathrm{i} 1}$ with two dominant-negative mutations (G203A and $\mathrm{A} 326 \mathrm{~S}^{34}$ ) was used to assemble a 
stable GPCR-G $\mathrm{G}_{\mathrm{i}}$ protein complex. These two cognate mutations also exist in engineered $\mathrm{G} \alpha_{\mathrm{q}}$ and $\mathrm{G} \alpha_{\mathrm{s}}$ (Extended Data Fig. 2b). Receptor, rat H6-G $\beta$, bovine $\mathrm{G} \gamma$, and the specific $\mathrm{G} \alpha$ subunit were coexpressed in Spodoptera frugiperda ( $s f 9$ ) insect cells (Invitrogen) as previously described ${ }^{52}$. In addition, GST-Ric-8A (a gift from Dr. B. Kobilka) was applied to improve the expression of $\mathrm{G}_{\mathrm{q}}$.

ScFv16 was applied to improve the protein stability of $\mathrm{CCK}_{\mathrm{A}} \mathrm{R}-\mathrm{G}_{\mathrm{q}}$ and $\mathrm{CCK}_{\mathrm{A}} \mathrm{R}-\mathrm{G}_{\mathrm{i}}$ complex samples. The monomeric scFv16 was prepared as previously reported ${ }^{53}$. Cell pellets of the coexpression culture were thawed and lysed in $20 \mathrm{mM}$ HEPES, pH 7.4, $100 \mathrm{mM} \mathrm{NaCl}, 10 \%$ glycerol, $5 \mathrm{mM} \mathrm{MgCl} 2$, and $10 \mathrm{mM} \mathrm{CaCl}_{2}$ supplemented with EDTA-free protease inhibitor cocktail (TargetMol). $\mathrm{CCK}_{\mathrm{A}} \mathrm{R}-\mathrm{G}$ protein complexes were assembled at room temperature (RT) for $1 \mathrm{~h}$ by the addition of $10 \mu \mathrm{M} \mathrm{CCK}-8$ (GenScript) and $25 \mathrm{mU} / \mathrm{mL}$ apyrase. Then the lysate was solubilized in $0.5 \% \mathrm{LMNG}, 0.1 \% \mathrm{CHS}$, and the soluble fraction was purified by nickel affinity chromatography (Ni Smart Beads 6FF, SMART Lifesciences). In the case of $\mathrm{CCK}_{\mathrm{A}} \mathrm{R}-\mathrm{G}_{\mathrm{i}}$ and $\mathrm{CCK}_{\mathrm{A}} \mathrm{R}-\mathrm{G}_{\mathrm{q}}$ complexes, a 3 molar excess of scFv16 was added to the protein elute. The mixture was incubated with amylose resin for $2 \mathrm{~h}$ at $4{ }^{\circ} \mathrm{C}$. The excess $\mathrm{G}$ protein and scFv16 were washed with 20 column volumes of 20 mM HEPES, pH 7.4, $100 \mathrm{mM} \mathrm{NaCl}, 10 \%$ glycerol, $0.01 \%$ LMNG, $0.002 \%$ CHS, and $2 \mu \mathrm{M} \mathrm{CCK}-$ 8. TEV protease was then included to remove the $\mathrm{N}$ terminal fusion tags of $\mathrm{CCK}_{\mathrm{A}} \mathrm{R}$. After $1 \mathrm{~h}$ incubation at RT, the flow-through was collected, concentrated, and injected onto a Superdex 200 10/300 column equilibrated in the buffer containing $20 \mathrm{mM}$ HEPES, $\mathrm{pH} 7.4,100 \mathrm{mM} \mathrm{NaCl}, 0.00075 \%$ LMNG, $0.00025 \%$ GDN, $0.0002 \%$ CHS, and $10 \mu \mathrm{M}$ CCK- 8 . The monomeric complex peak was collected and concentrated to about $5 \mathrm{mg} / \mathrm{mL}$ for cryo-EM studies.

\section{Cryo-EM grid preparation and image collection}

For preparation of cryo-EM grids, $2.5 \mu \mathrm{L}$ of each purified $\mathrm{CCK}_{\mathrm{A}} \mathrm{R}-\mathrm{G}$ protein complex was applied individually onto the glow-discharged holey carbon grids (Quantifoil, Au300 R1.2/1.3) in a Vitrobot chamber (FEI Vitrobot Mark IV). The Vitrobot chamber was set to $100 \%$ humidity at $4^{\circ} \mathrm{C}$. Extra samples were blotted for $2 \mathrm{~s}$ and were vitrified by plunging into liquid ethane. Grids were stored in liquid nitrogen for condition screening and data collection usage.

Automatic data collection of CCK-8- $\mathrm{CCK}_{\mathrm{A}} \mathrm{R}-\mathrm{G}$ protein complexes were performed on a FEI Titan Krios operated at $300 \mathrm{kV}$. The microscope was operated with a nominal magnification of $81,000 \times$ in counting mode, corresponding to a pixel size of $1.045 \AA$ for the micrographs. A total of 5,415 movies for the dataset of CCK-8- $\mathrm{CCK}_{\mathrm{A}} \mathrm{R}-\mathrm{G}_{\mathrm{q}}-\mathrm{scFv} 16$ complex, 5008 movies for the dataset of CCK-8-CCK ${ }_{A} R-G_{s}$ complex, and 4,811 movies for the dataset of CCK-8-CCK ${ }_{A} \mathrm{R}-\mathrm{G}_{\mathrm{i}}-\mathrm{ScFv} 16$ complex were collected, respectively, by a Gatan K3 Summit direct electron detector with a Gatan energy filter (operated with a slit width of $20 \mathrm{eV}$ ) (GIF) using the SerialEM software. The images were recorded at a dose rate of about $26.7 \mathrm{e} / \AA^{2} / \mathrm{s}$ with a defocus ranging from -0.5 to $-3.0 \mu \mathrm{m}$. The total exposure time was $3 \mathrm{~s}$ and intermediate frames were recorded in $0.083 \mathrm{~s}$ intervals, resulting in a total of 36 frames per micrograph. 


\section{Image processing and map reconstruction}

Image stacks were subjected to beam-induced motion correction and aligned using MotionCor 2.1. Contrast transfer function (CTF) parameters were estimated by Ctffind4. The data processing was performed using RELION-3.0 ${ }^{54}$. The micrographs with the measured resolution worse than $4.0 \AA$ and micrographs imaged within carbon area were discarded, generating 3,806 micrographs for CCK-8- $\mathrm{CCK}_{\mathrm{A}} \mathrm{R}-\mathrm{G}_{\mathrm{q}}-\mathrm{scFv} 16$ dataset, 4,963 micrographs for CCK-8- $\mathrm{CCK}_{\mathrm{A}} \mathrm{R}-\mathrm{G}_{\mathrm{s}}$ dataset, and 4,543 micrographs for $\mathrm{CCK}-8-\mathrm{CCK}_{\mathrm{A}} \mathrm{R}-\mathrm{G}_{\mathrm{i}}-\mathrm{scFv} 16$ dataset for further data processing. Particle selection, 2D and 3D classifications were performed on a binned dataset with a pixel size of $2.09 \AA$. About 2,000 particles were manually selected and subjected to 2D classification. Representative averages were chosen as template for particle auto-picking. The auto-picking process produced 3,405,355 particles for CCK-8-CCK ${ }_{A} R-G_{q}-s c F v 16$ complex, 4,680,972 particles for CCK-8-CCK ${ }_{A} R-G_{s}$ complex, and 4,270,010 particles for CCK-8-CCK ${ }_{A} \mathrm{R}-\mathrm{G}_{\mathrm{i}}-\mathrm{scFv} 16$ complex, which were subjected to reference-free $2 \mathrm{D}$ classifications to discard bad particles. Initial reference map models for 3D classification were generated by Relion using the representative $2 \mathrm{D}$ averages. For CCK-8- $\mathrm{CCK}_{\mathrm{A}} \mathrm{R}-$ $\mathrm{G}_{\mathrm{q}}-\mathrm{scFv} 16$ complex, the particles selected from 2D classification were subjected to 6 rounds $3 \mathrm{D}$ classifications, resulting in a single well-defined subset with 555,628 particles. For CCK-8$\mathrm{CCK}_{\mathrm{A}} \mathrm{R}-\mathrm{G}_{\mathrm{s}}$ complex, the particles resulting from $2 \mathrm{D}$ classification were subjected to 5 rounds $3 \mathrm{D}$ classifications, resulting in two well-defined subsets with 499,924 particles. For CCK-8- $\mathrm{CCK}_{\mathrm{A}} \mathrm{R}-$ $\mathrm{G}_{\mathrm{i}-\mathrm{scFv}} 16$ complex, the particles selected from 2D classification were subjected to 7 rounds $3 \mathrm{D}$ classifications, resulting in two well-defined subsets with 140,602 particles. Further 3D refinement, CTF refinement, Bayesian polishing and DeepEnhancer processing generated density maps with an indicated global resolution of $2.9 \AA$ for CCK-8- $\mathrm{CCK}_{\mathrm{A}} \mathrm{R}-\mathrm{G}_{\mathrm{q}}-\mathrm{ScFv} 16$ complex, $3.1 \AA$ for CCK-8$\mathrm{CCK}_{\mathrm{A}} \mathrm{R}-\mathrm{G}_{\mathrm{s}}$ complex, and $3.2 \AA$ for $\mathrm{CCK}-8-\mathrm{CCK}_{\mathrm{A}} \mathrm{R}-\mathrm{G}_{\mathrm{i}}-\mathrm{scFv} 16$ complex, respectively, at a Fourier shell correlation of 0.143 .

\section{Model building and refinement}

For the $\mathrm{CCK}_{\mathrm{A}} \mathrm{R}-\mathrm{G}_{\mathrm{q}}$ complex, the initial $\mathrm{G}_{\mathrm{q}}$ protein and $\mathrm{scFv} 16$ model were adopted from the cryoEM structure of the $\mathrm{M}_{1} \mathrm{R}-\mathrm{G}_{11}$ protein complex (PDB: 6OIJ) ${ }^{21}$. The initial $\mathrm{CCK}_{\mathrm{A}} \mathrm{R}$ model was generated by an online homology model building tool ${ }^{55}$. All models were docked into the EM density map using Chimera ${ }^{56}$, followed by iterative manual adjustment and rebuilding in COOT ${ }^{57}$ and ISOLDE ${ }^{58}$, and real-space refinement using Phenix programs ${ }^{59}$. The model statistics were validated using Phenix comprehensive validation. A model of the refined $\mathrm{CCK}_{\mathrm{A}} \mathrm{R}$ from the $\mathrm{CCK}_{\mathrm{A}} \mathrm{R}-$ $\mathrm{G}_{\mathrm{q}}$ complex was used for the other two complexes. Models from PTH1R- $\mathrm{G}_{\mathrm{s}}(\mathrm{PDB}$ : 6NBF) and FPR2- $\mathrm{G}_{\mathrm{i}}$ (PDB: 6OMM) were used as templates for the model building of $\mathrm{G}_{\mathrm{s}}$ in the $\mathrm{CCK}_{\mathrm{A}} \mathrm{R}-\mathrm{G}_{\mathrm{s}}$ complex and $\mathrm{G}_{\mathrm{i} 1}-\mathrm{scFv} 16$ in the $\mathrm{CCK}_{\mathrm{A}} \mathrm{R}-\mathrm{G}_{\mathrm{i}}$ complex, respectively. Then the fitted models were built the same way as the $\mathrm{CCK}_{\mathrm{A}} \mathrm{R}-\mathrm{G}_{\mathrm{q}}$ complex. The final refinement statistics are provided in Extended Data Table 1. 


\section{Radiolabeled ligand-binding assay}

The WT or mutant $\mathrm{CCK}_{\mathrm{A}}$ Rs were transiently transfected into HEK 293T/17 cells (purchased from the Cell Bank at the Chinese Academy of Sciences) which were cultured in poly-D-lysine coated 96-well plate. Twenty-four h later, the cells were washed twice and incubated with blocking buffer (DMEM medium supplemented with $33 \mathrm{mM}$ HEPES, and $0.1 \%$ (w/v) BSA, $\mathrm{pH} 7.4$ ) for $2 \mathrm{~h}$ at $37^{\circ} \mathrm{C}$. After three times washes by cold-ice PBS, the cells were treated by a constant concentration of ${ }^{125} \mathrm{I}$ CCK-8 (40 pM, PerkinElmer) plus 8 different doses of CCK-8 (1 pM to $10 \mu \mathrm{M})$ for $3 \mathrm{~h}$ at RT. Cells were washed three times with ice-cold PBS and lysed by $50 \mu \mathrm{L}$ lysis buffer (PBS supplemented with $20 \mathrm{mM}$ Tris- $\mathrm{HCl}$ and $1 \%(\mathrm{v} / \mathrm{v})$ Triton X-100, $\mathrm{pH}$ 7.4). Subsequently, the plates were counted for radioactivity (counts per minute, CPM) in a scintillation counter (MicroBeta ${ }^{2}$ plate counter, PerkinElmer) using $150 \mu$ l scintillation cocktail (OptiPhase SuperMix, PerkinElmer).

\section{G protein dissociation assay}

G protein dissociation was monitored by BRET (bioluminescence resonance energy transfer) experiments performed as previously reported ${ }^{60}$. Briefly, a C-terminal fragment of the GRK3 (GRK3ct) fused to a luciferase serves as a BRET donor. G $\beta \gamma$ dimer is labeled with a fluorescent protein Venus, a BRET acceptor. Upon G protein heterotrimer activation, free $\mathrm{G} \beta \gamma$-Venus is released and binds to membrane-associated GRK3ct-luciferase, leading to an increased signal detectable by BRET.

HEK 293T/17 cells were seeded onto $10 \mu \mathrm{g} / \mathrm{mL}$ Matrigel-coated 6 -well plate $\left(1 \times 10^{6}\right.$ cells $/$ well $)$. After $4 \mathrm{~h}$ culture, WT or mutant $\mathrm{CCK}_{\mathrm{A}} \mathrm{R}(0.84 \mu \mathrm{g}), \mathrm{G} \alpha\left(\mathrm{G} \alpha_{\mathrm{q}}, \mathrm{G} \alpha_{\mathrm{s}}\right.$, and $\mathrm{G} \alpha_{\mathrm{i}}, 2.1 \mu \mathrm{g}$ each), $\mathrm{G} \beta(0.42$ $\mu \mathrm{g}), \mathrm{G} \gamma(0.42 \mu \mathrm{g})$, and GRK $(0.42 \mu \mathrm{g})$ were transiently transfected with Lipofectamine ${ }^{\mathrm{TM}}$ LTX Reagent (Invitrogen). Twenty-four hours post-transfection, cells were washed once with DMEM medium (no phenol red) and detached by EDTA. Cells were then harvested with centrifugation at $1000 \mathrm{rpm}$ for $5 \mathrm{~min}$ and resuspended in DMEM medium. Approximately 75,000 cells per well were distributed in 96-well flat-bottomed white microplates (PerkinElmer). The NanoBRET substrate (furimazine, $25 \mu \mathrm{L} /$ well, Promega) was added, and the BRET signal ( $535 \mathrm{~nm} / 475 \mathrm{~nm}$ ratio) was determined using an EnVision multilabel plate reader (PerkinElmer). The average baseline value recorded before CCK-8 stimulation was subtracted from BRET signal values.

\section{NanoBiT G-protein recruitment assay}

375 The recruitment of $\mathrm{CCK}_{\mathrm{A}} \mathrm{R}$ to $\mathrm{G}_{\mathrm{i}}$-protein was detected in $s f 9$ cells using NanoBiT method as previously reported ${ }^{61}$. Briefly, the LgBiT fragment of NanoBiT luciferase was fused to the Cterminus of $\mathrm{CCK}_{\mathrm{A}} \mathrm{R}$. SmBiT was fused to the C-terminus of $\mathrm{G} \beta$ subunit with a 15 -amino acid flexible linker. $\mathrm{CCK}_{\mathrm{A}} \mathrm{R}-\mathrm{LgBiT}, \mathrm{G} \alpha_{\mathrm{i}}$, SmBiT-fused human $\mathrm{G} \beta 1$ and human $\mathrm{G} \gamma 2$ were co-expressed in $s f 9$ insect cells. Cell pellets were collected by centrifugation after infection for $48 \mathrm{~h}$. The cell

380 suspension was dispensed in a 96-well plate (64,000 cells per well) at a volume of $80 \mu \mathrm{L}$ diluted in the assay buffer (HBSS buffer supplemented with 10 mM HEPES, pH 7.4) and incubated for 30 
$\min$ at $37^{\circ} \mathrm{C}$. The cells were then reacted with $10 \mu \mathrm{L}$ of $50 \mathrm{mM}$ coelenterazine $\mathrm{H}$ (Yeasen) for $2 \mathrm{~h}$ at RT. Luminescence signal was measured using an EnVision plate reader (PerkinElmer) at $30 \mathrm{~s}$ intervals $\left(25^{\circ} \mathrm{C}\right)$. The baseline was measured before CCK- 8 addition for 8 intervals, and the measurements continued for 20 intervals following ligand addition. Data were corrected to baseline measurements and the results were analyzed using GraphPad Prism 8.0 (Graphpad Software Inc.).

\section{NanoBiT G-protein dissociation assay}

$\mathrm{G}_{\mathrm{s}}$ activation was measured by a NanoBiT dissociation assay. G protein NanoBiT split luciferase constructs were generated by fusing the $\mathrm{LgBiT}$ in $\mathrm{G}_{\mathrm{s}}$ and the $\mathrm{SmBiT}$ to $\mathrm{G} \gamma$ (a gift from Dr. Asuka Inoue, Tohoku University) as previously reported ${ }^{62}$. In brief, HEK 293T/17 cells were plated in 10 $\mathrm{cm}$ plates at a density of $3 \times 10^{6}$ cells per plate. After $24 \mathrm{~h}$, cells were transfected with $1.62 \mu \mathrm{g}$ plasmids of receptor, $0.81 \mu \mathrm{g} \mathrm{G} \alpha_{\mathrm{s}}$-LgBiT, $4.1 \mu \mathrm{g} \mathrm{G} \beta$, and $4.1 \mu \mathrm{g}$ SmBiT-G $\gamma$ using Lipofectamine ${ }^{\mathrm{TM}}$ LTX Reagent (Invitrogen). The transiently transfected cells were then seeded into poly-D-lysine coated 96-well plates (50,000 cells per well) and grown overnight before incubation in an assay buffer. The measurement of luminescence signal was identical to the steps described above.

\section{Surface expression assay}

HEK 293T/17 cells were seeded into a 6-well plate and incubated overnight. After transient transfection with WT or mutant plasmids for $24 \mathrm{~h}$, the cells were collected and blocked with $5 \%$ BSA in PBS at RT for 15 min and incubated with primary anti-Flag antibody (1:300, Sigma-Aldrich) at RT for $1 \mathrm{~h}$. The cells were then washed three times with PBS containing 1\% BSA followed by 1 $\mathrm{h}$ incubation with donkey anti-mouse Alexa Fluor 488-conjugated secondary antibody (1:1000, ThermoFisher) at $4{ }^{\circ} \mathrm{C}$ in the dark. After three washes, the cells were resuspended in $200 \mu \mathrm{l}$ of PBS containing $1 \%$ BSA for detection in a NovoCyte flow cytometer (ACEA Biosciences) utilizing laser excitation and emission wavelengths of $488 \mathrm{~nm}$ and $519 \mathrm{~nm}$, respectively. For each assay point, approximately 15,000 cellular events were collected, and the total fluorescence intensity of positive expression cell population was calculated.

\section{Molecular docking}

Before docking, hydrogens were added to $\mathrm{CCK}_{\mathrm{A}} \mathrm{R}$ and the whole system coordinates were optimized with a $\mathrm{pH}$ of 7.0. A grid file was then generated on the peptide pocket in our $\mathrm{G}_{\mathrm{q}}$-coupled $\mathrm{CCK}_{\mathrm{A}} \mathrm{R}$ structure. Small molecule ligands Glaxo-11p, GW-5823, and CE-326597 were prepared in the OPLS3 force field with a $\mathrm{pH}$ of 7.0 to generate 3D structures. Finally, glide docking with standard precision was applied to all ligands and the structures with the best docking score were picked as outputs.

\section{Acknowledgments}

We thank Kirill A. Martemyanov for expert advice on BRET assay. The cryo-EM data were 
collected at the Cryo-Electron Microscopy Research Center, Shanghai Institute of Materia Medica (SIMM). The authors thank the staff at the SIMM Cryo-Electron Microscopy Research Center for their technical support. Funding: This work was partially supported by the Ministry of Science and Technology (China) grant 2018YFA0507002 (H.E.X.) and 2018YFA0507000 (M.-W.W.); National Natural Science Foundation of China 31770796 (Y.J.), 81872915 (M.-W.W.), 81773792 (D.Y.), and 81973373 (D.Y.); National Science and Technology Major Project of China - Key New Drug Creation and Manufacturing Program 2018ZX09735-001 (M.-W.W.), 2018ZX09711002-002-002 (Y.J.), and 2018ZX09711002-002-005 (D.Y.); Shanghai Municipal Science and Technology Commission Major Project 2019SHZDZX02 (H.E.X.); the Strategic Priority Research Program of Chinese Academy of Sciences (XDB37030103 to H.E.X.); Shanghai Sailing Program 19YF1457600 (Q.F.L.); Wellcome Trust Principal Research Fellowship 209407/Z/17/Z (T.C.); and Novo Nordisk-CAS Research Fund grant NNCAS-2017-1-CC (D.Y.).

\section{Author contributions}

Q.F.L. screened the expression constructs, optimized the $\mathrm{CCK}_{\mathrm{A}} \mathrm{R}-\mathrm{G}$ protein complexes, prepared the protein samples for final structure determination, participated in cryo-EM grid inspection and data collection, built and refined the structure models, prepared the constructs for functional assays, analyzed the structures, and prepared the figures and wrote the initial manuscript; Y.W.Z. performed cryo-EM grid preparation, data collection, structure determination, and participated in protein sample optimization, figure and manuscript preparation; T.C. helped build and refine the structure model; X.H.H. performed the molecular docking; J.D. and W.C.Y. designed G protein constructs; F.L.Z. participated in data analysis; B.L.W. and Q.Z. participated in research supervising; H.E.X. conceived and supervised the project, analyzed the structures, and initiated collaborations with M.W.W., supervised Q.F.L., Z.Y.W., F.L.Z., J.D., W.C.Y.; M.-W.W and D.H.Y. supervised X.Q.C., A.T.D., and C.Y.Y. in G protein assay development and data analysis; M.-W.W. participated in manuscript writing; Y.J. supervised the studies, performed the structural analysis, and prepared the figures and wrote the manuscript with input from all co-authors.

\section{Competing interests}

All authors declare no competing interests.

\section{Data availability}

All data is available in the main text or the supplementary materials. Materials are available from the corresponding authors upon reasonable request.

\section{References}

1 Bowers, M. E., Choi, D. C. \& Ressler, K. J. Neuropeptide regulation of fear and anxiety: Implications of cholecystokinin, endogenous opioids, and neuropeptide Y. Physiol Behav 107, 
699-710, doi:10.1016/j.physbeh.2012.03.004 (2012).

2 Rehfeld, J. F., Friis-Hansen, L., Goetze, J. P. \& Hansen, T. V. The biology of cholecystokinin and gastrin peptides. Curr Top Med Chem 7, 1154-1165, doi:10.2174/156802607780960483 (2007).

3 Wank, S. A. Cholecystokinin receptors. Am J Physiol 269, G628-646, doi:10.1152/ajpgi.1995.269.5.G628 (1995).

4 Dufresne, M., Seva, C. \& Fourmy, D. Cholecystokinin and gastrin receptors. Physiol Rev 86, 805-847, doi:10.1152/physrev.00014.2005 (2006).

5 Moran, T. H., Smith, G. P., Hostetler, A. M. \& McHugh, P. R. Transport of cholecystokinin (CCK) binding sites in subdiaphragmatic vagal branches. Brain Res 415, 149-152, doi:10.1016/0006-8993(87)90278-2 (1987).

6 Weatherford, S. C., Chiruzzo, F. Y. \& Laughton, W. B. Satiety induced by endogenous and exogenous cholecystokinin is mediated by CCK-A receptors in mice. Am J Physiol 262, R574578, doi:10.1152/ajpregu.1992.262.4.R574 (1992).

7 Miller, L. J., Holicky, E. L., Ulrich, C. D. \& Wieben, E. D. Abnormal processing of the human cholecystokinin receptor gene in association with gallstones and obesity. Gastroenterology 109, 1375-1380, doi:10.1016/0016-5085(95)90601-0 (1995).

4758 Hewson, G., Leighton, G. E., Hill, R. G. \& Hughes, J. The cholecystokinin receptor antagonist L364,718 increases food intake in the rat by attenuation of the action of endogenous cholecystokinin. Br J Pharmacol 93, 79-84, doi:10.1111/j.1476-5381.1988.tb11407.x (1988).

9 Jordan, J. et al. Stimulation of cholecystokinin-A receptors with GI181771X does not cause weight loss in overweight or obese patients. Clin Pharmacol Ther 83, 281-287, doi:10.1038/sj.clpt.6100272 (2008).

10 Elliott, R. L. et al. Discovery of N-benzyl-2-[(4S)-4-(1H-indol-3-ylmethyl)-5-oxo-1-phenyl-4,5dihydro-6H-[1,2,4]tri azolo[4,3-a][1,5]benzodiazepin-6-yl]-N-isopropylacetamide, an orally active, gut-selective CCK1 receptor agonist for the potential treatment of obesity. Bioorg Med Chem Lett 20, 6797-6801, doi:10.1016/j.bmcl.2010.08.115 (2010).

48511 Gigoux, V. et al. Arginine 197 of the cholecystokinin-A receptor binding site interacts with the sulfate of the peptide agonist cholecystokinin. Protein Sci 8, 2347-2354, doi:10.1110/ps.8.11.2347 (1999).

12 Escrieut, C. et al. The biologically crucial C terminus of cholecystokinin and the non-peptide agonist SR-146,131 share a common binding site in the human CCK1 receptor. Evidence for a 490 crucial role of Met-121 in the activation process. J Biol Chem 277, 7546-7555, doi:10.1074/jbc.M108563200 (2002).

13 Archer-Lahlou, E. et al. Molecular mechanism underlying partial and full agonism mediated by the human cholecystokinin-1 receptor. J Biol Chem 280, 10664-10674, doi:10.1074/jbc.M409451200 (2005).

49514 Archer-Lahlou, E. et al. Modeled structure of a G-protein-coupled receptor: The 
Cholecystokinin-1 receptor. J Med Chem 48, 180-191, doi:10.1021/jm049886y (2005).

15 Miller, L. J. \& Gao, F. Structural basis of cholecystokinin receptor binding and regulation. Pharmacol Ther 119, 83-95, doi:10.1016/j.pharmthera.2008.05.001 (2008).

16 Rasmussen, S. G. et al. Crystal structure of the beta2 adrenergic receptor-Gs protein complex. Nature 477, 549-555, doi:10.1038/nature10361 (2011).

17 Zhang, Y. et al. Cryo-EM structure of the activated GLP-1 receptor in complex with a G protein. Nature 546, 248-253, doi:10.1038/nature22394 (2017).

18 Kang, Y. et al. Cryo-EM structure of human rhodopsin bound to an inhibitory G protein. Nature 558, 553-558, doi:10.1038/s41586-018-0215-y (2018).

19 Kato, H. E. et al. Conformational transitions of a neurotensin receptor 1-Gi1 complex. Nature 572, 80-85, doi:10.1038/s41586-019-1337-6 (2019).

20 Yang, F. et al. Structural basis of GPBAR activation and bile acid recognition. Nature, doi:10.1038/s41586-020-2569-1 (2020).

21 Maeda, S., Qu, Q., Robertson, M. J., Skiniotis, G. \& Kobilka, B. K. Structures of the M1 and M2 muscarinic acetylcholine receptor/G-protein complexes. Science 364, 552-557, doi:10.1126/science.aaw5188 (2019).

$22 \mathrm{Kim}, \mathrm{K}$. et al. Structure of a Hallucinogen-Activated Gq-Coupled 5-HT2A Serotonin Receptor. Cell 182, 1574-1588 e1519, doi:10.1016/j.cell.2020.08.024 (2020).

23 Qiao, A. et al. Structural basis of Gs and Gi recognition by the human glucagon receptor. Science 367, 1346-1352, doi:10.1126/science.aaz5346 (2020).

24 Okashah, N. et al. Variable G protein determinants of GPCR coupling selectivity. Proc Natl Acad Sci U S A 116, 12054-12059, doi:10.1073/pnas.1905993116 (2019).

25 Rose, A. S. et al. Position of transmembrane helix 6 determines receptor G protein coupling specificity. J Am Chem Soc 136, 11244-11247, doi:10.1021/ja5055109 (2014).

26 Hauser, A. S. et al. Pharmacogenomics of GPCR Drug Targets. Cell 172, 41-54 e19, doi:10.1016/j.cell.2017.11.033 (2018).

27 Paulssen, R. H., Fraeyman, N. \& Florholmen, J. Activation of phospholipase C by cholecystokinin receptor subtypes with different G-protein-coupling specificities in hormonesecreting pancreatic cell lines. Biochem Pharmacol 60, 865-875, doi:10.1016/s00062952(00)00383-x (2000).

$28 \mathrm{Wu}$, V. et al. First intracellular loop of the human cholecystokinin-A receptor is essential for cyclic AMP signaling in transfected HEK-293 cells. J Biol Chem 272, 9037-9042, doi:10.1074/jbc.272.14.9037 (1997).

29 Scemama, J. L. et al. CCK and gastrin inhibit adenylate cyclase activity through a pertussis toxin-sensitive mechanism in the tumoral rat pancreatic acinar cell line AR 4-2J. FEBS Lett 242, 61-64, doi:10.1016/0014-5793(88)80985-2 (1988).

30 Sabbatini, M. E., Bi, Y., Ji, B., Ernst, S. A. \& Williams, J. A. CCK activates RhoA and Rac1 differentially through Galpha13 and Galphaq in mouse pancreatic acini. Am J Physiol Cell 
Physiol 298, C592-601, doi:10.1152/ajpcell.00448.2009 (2010).

31 Le Page, S. L., Bi, Y. \& Williams, J. A. CCK-A receptor activates RhoA through G alpha 12/13 in NIH3T3 cells. Am J Physiol Cell Physiol 285, C1197-1206, doi:10.1152/ajpcell.00083.2003 (2003).

32 Maeda, S. et al. Development of an antibody fragment that stabilizes GPCR/G-protein complexes. Nat Commun 9, doi:ARTN 371210.1038/s41467-018-06002-w (2018).

33 Carpenter, B., Nehme, R., Warne, T., Leslie, A. G. \& Tate, C. G. Structure of the adenosine $\mathrm{A}(2 \mathrm{~A})$ receptor bound to an engineered $\mathrm{G}$ protein. Nature 536, 104-107, doi:10.1038/nature18966 (2016).

$34 \mathrm{Liu}$, P. et al. The structural basis of the dominant negative phenotype of the Galphailbeta1gamma2 G203A/A326S heterotrimer. Acta Pharmacol Sin 37, 1259-1272, doi:10.1038/aps.2016.69 (2016).

35 Ballesteros, J. A. \& Weinstein, H. Integrated methods for the construction of three-dimensional models and computational probing of structure-function relations in $\mathrm{G}$ protein-coupled receptors. Meth Neurosci 25, 366-428, doi:10.1016/S1043-9471(05)80049-7 (1995).

36 Shiimura, Y. et al. Structure of an antagonist-bound ghrelin receptor reveals possible ghrelin recognition mode. Nat Commun 11, 4160, doi:10.1038/s41467-020-17554-1 (2020).

37 Wingler, L. M. et al. Angiotensin and biased analogs induce structurally distinct active conformations within a GPCR. Science 367, 888-+, doi:10.1126/science.aay9813 (2020).

38 Hong, C. et al. Structures of active-state orexin receptor 2 rationalize peptide and small-molecule agonist recognition and receptor activation. Nat Commun 12, 815, doi:10.1038/s41467-02121087-6 (2021).

39 Zhou, F. et al. Molecular basis of ligand recognition and activation of human V2 vasopressin receptor. Cell Res, doi:10.1038/s41422-021-00480-2 (2021).

40 Gigoux, V. et al. Arginine 336 and asparagine 333 of the human cholecystokinin-A receptor binding site interact with the penultimate aspartic acid and the C-terminal amide of cholecystokinin. J Biol Chem 274, 20457-20464, doi:10.1074/jbc.274.29.20457 (1999).

41 Henke, B. R. et al. Optimization of 3-(1H-indazol-3-ylmethyl)-1,5-benzodiazepines as potent, orally active CCK-A agonists. J Med Chem 40, 2706-2725, doi:10.1021/jm970265x (1997).

42 Aquino, C. J. et al. Discovery of 1,5-benzodiazepines with peripheral cholecystokinin (CCK-A) receptor agonist activity. 1. Optimization of the agonist "trigger". J Med Chem 39, 562-569, doi:10.1021/jm950626d (1996).

43 Flock, T. et al. Universal allosteric mechanism for G alpha activation by GPCRs. Nature 524, 173-+, doi:10.1038/nature14663 (2015).

$44 \mathrm{DeV} r e e, \mathrm{~B}$. T. et al. Allosteric coupling from G protein to the agonist-binding pocket in GPCRs. Nature 535, 182-186, doi:10.1038/nature18324 (2016).

57045 Garcia-Nafria, J. \& Tate, C. G. Cryo-EM structures of GPCRs coupled to Gs, Gi and Go. Mol Cell Endocrinol 488, 1-13, doi:10.1016/j.mce.2019.02.006 (2019). 
46 Garcia-Nafria, J., Nehme, R., Edwards, P. C. \& Tate, C. G. Cryo-EM structure of the serotonin 5-HT1B receptor coupled to heterotrimeric Go. Nature 558, 620-623, doi:10.1038/s41586-0180241-9 (2018).

$47 \mathrm{Kim}, \mathrm{H}$. R. et al. Structural mechanism underlying primary and secondary coupling between GPCRs and the Gi/o family. Nat Commun 11, 3160, doi:10.1038/s41467-020-16975-2 (2020).

48 Albert, P. R. \& Robillard, L. G protein specificity: traffic direction required. Cell Signal 14, 407418, doi:10.1016/s0898-6568(01)00259-5 (2002).

49 Woehler, A. \& Ponimaskin, E. G. G protein--mediated signaling: same receptor, multiple effectors. Curr Mol Pharmacol 2, 237-248, doi:10.2174/1874467210902030237 (2009).

$50 \mathrm{Koehl}$, A. et al. Structure of the micro-opioid receptor-Gi protein complex. Nature 558, 547-552, doi:10.1038/s41586-018-0219-7 (2018).

51 Draper-Joyce, C. J. et al. Structure of the adenosine-bound human adenosine A1 receptor-Gi complex. Nature 558, 559-563, doi:10.1038/s41586-018-0236-6 (2018).

52 Duan, J. et al. Cryo-EM structure of an activated VIP1 receptor-G protein complex revealed by a NanoBiT tethering strategy. Nat Commun 11, 4121, doi:10.1038/s41467-020-17933-8 (2020).

53 Zhuang, Y. et al. Structure of formylpeptide receptor 2-Gi complex reveals insights into ligand recognition and signaling. Nat Commun 11, 885, doi:10.1038/s41467-020-14728-9 (2020).

54 Scheres, S. H. RELION: implementation of a Bayesian approach to cryo-EM structure determination. J Struct Biol 180, 519-530, doi:10.1016/j.jsb.2012.09.006 (2012).

55 Kelley, L. A., Mezulis, S., Yates, C. M., Wass, M. N. \& Sternberg, M. J. The Phyre2 web portal for protein modeling, prediction and analysis. Nat Protoc 10, 845-858, doi:10.1038/nprot.2015.053 (2015).

56 Pettersen, E. F. et al. UCSF Chimera--a visualization system for exploratory research and analysis. J Comput Chem 25, 1605-1612, doi:10.1002/jcc.20084 (2004).

57 Emsley, P. \& Cowtan, K. Coot: model-building tools for molecular graphics. Acta Crystallogr D Biol Crystallogr 60, 2126-2132, doi:10.1107/S0907444904019158 (2004).

58 Croll, T. I. ISOLDE: a physically realistic environment for model building into low-resolution electron-density maps. Acta Crystallogr D Struct Biol 74, 519-530, doi: 10.1107/S2059798318002425 (2018).

59 Adams, P. D. et al. PHENIX: a comprehensive Python-based system for macromolecular structure solution. Acta Crystallogr D Biol Crystallogr 66, 213-221, doi:10.1107/S0907444909052925 (2010).

60 Masuho, I., Martemyanov, K. A. \& Lambert, N. A. Monitoring G Protein Activation in Cells with BRET. Methods Mol Biol 1335, 107-113, doi:10.1007/978-1-4939-2914-6_8 (2015).

$61 \mathrm{Xu}, \mathrm{P}$. et al. Structures of the human dopamine D3 receptor-Gi complexes. Mol Cell 81, 11471159 e1144, doi:10.1016/j.molcel.2021.01.003 (2021).

62 Inoue, A. et al. Illuminating G-Protein-Coupling Selectivity of GPCRs. Cell 177, 1933-1947 e1925, doi:10.1016/j.cell.2019.04.044 (2019). 


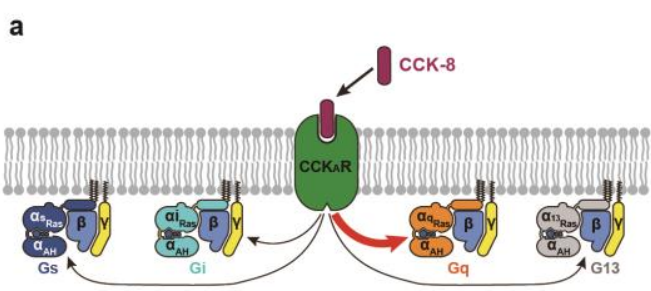

c

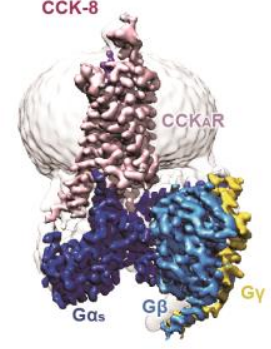

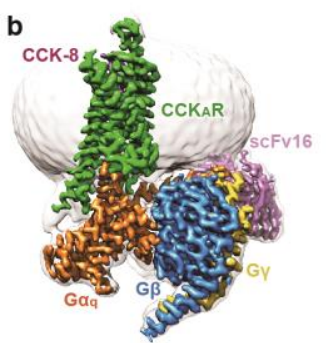

d

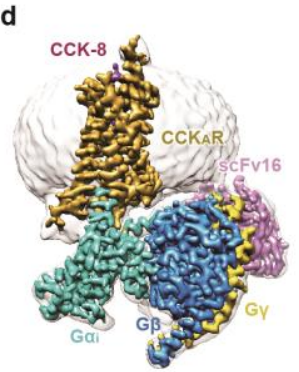

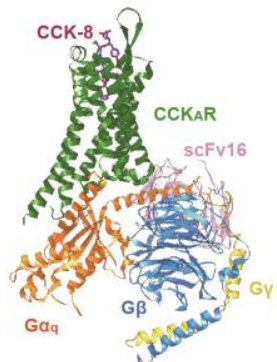

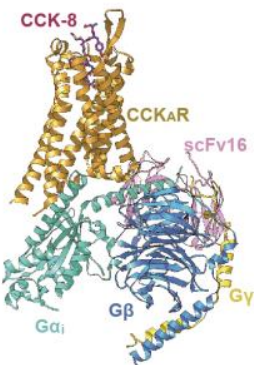

610

Fig. 1 | Cryo-EM structures of $\mathbf{C C K}_{\mathrm{A}} \mathbf{R}-\mathbf{G}$ protein complexes. a, Schematic illustration of $\mathrm{G}$ protein coupling promiscuity of $\mathrm{CCK}_{\mathrm{A}} \mathrm{R}$. b-d, Three-dimensional map (left panel) and the model (right panel) of the CCK-8-CCK ${ }_{\mathrm{A}} \mathrm{R}-\mathrm{G}_{\mathrm{q}}-\mathrm{scFv} 16(\mathbf{b}), \mathrm{CCK}-8-\mathrm{CCK}_{\mathrm{A}} \mathrm{R}-\mathrm{G}_{\mathrm{s}}(\mathbf{c})$, and CCK-8-CCK $\mathrm{A}_{\mathrm{A}} \mathrm{R}-$ $\mathrm{G}_{\mathrm{i}}-\mathrm{ScFv} 16$ (d) complexes. CCK-8, magenta; $\mathrm{CCK}_{\mathrm{A}} \mathrm{R}(\mathbf{b})$, green; $\mathrm{CCK}_{\mathrm{A}} \mathrm{R}(\mathbf{c})$, pink; $\mathrm{CCK}_{\mathrm{A}} \mathrm{R}(\mathbf{d})$; 615 dark yellow; $\mathrm{G} \alpha_{\mathrm{q}}$, orange; $\mathrm{G} \alpha_{\mathrm{s}}$, blue; $\mathrm{G} \alpha_{\mathrm{i}}$, cyan; $\mathrm{G} \beta$, light blue; $\mathrm{G} \gamma$, yellow; scFv16, light purple. 

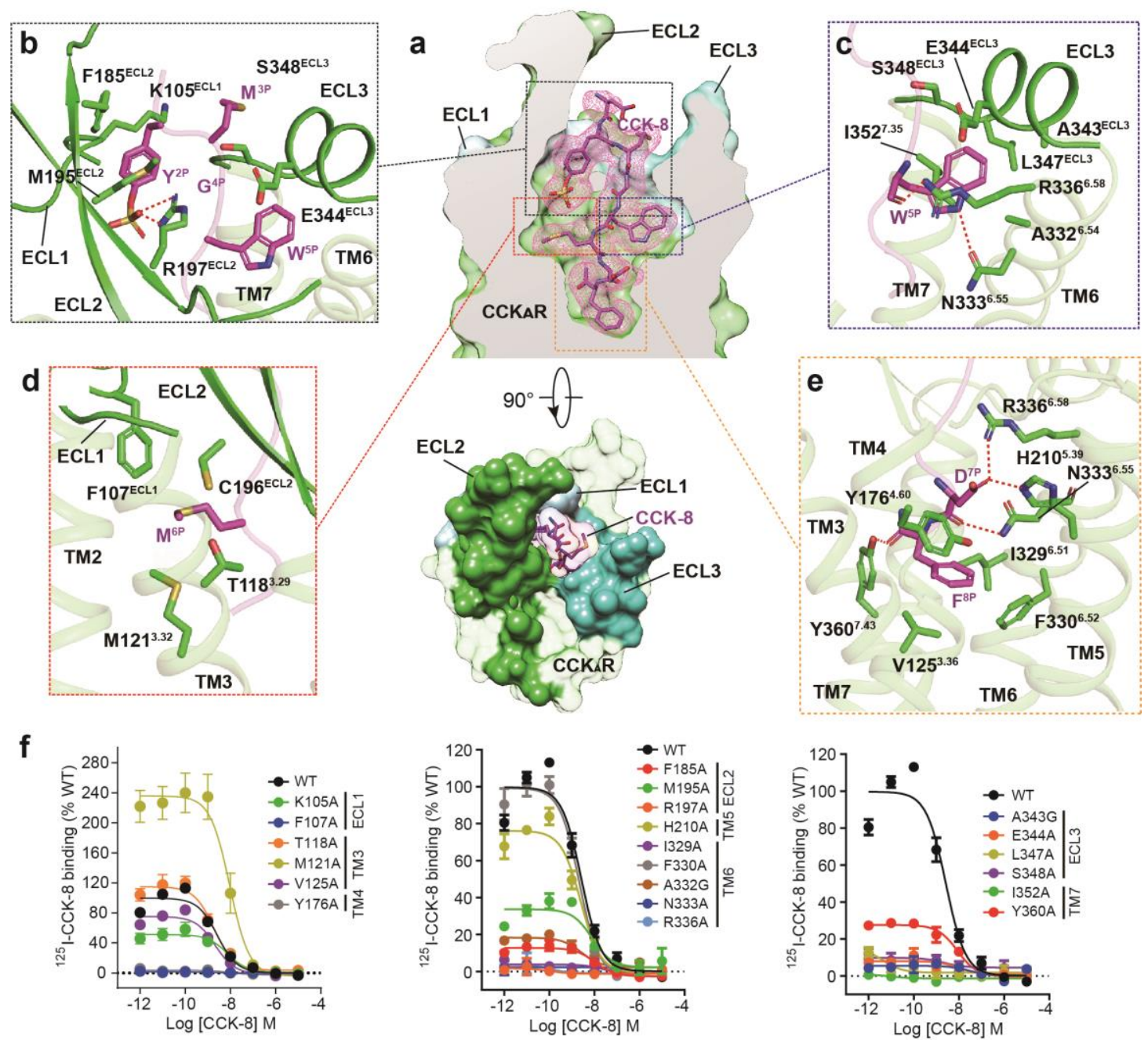

Fig. 2| Recognition of sulfated CCK-8 by $\mathbf{C C K}_{\mathrm{A}} \mathbf{R}$. a, CCK-8 sits in the orthosteric binding pocket of $\mathrm{CCK}_{\mathrm{A}} \mathrm{R}$ shown at side view (upper panel) and extracellular view (bottom panel). The density map of CCK-8 is shown as magenta mesh, and CCK-8 is displayed as magenta sticks. $\mathrm{CCK}_{\mathrm{A}} \mathrm{R}$ is shown in green as a cut-away surface (upper panel). ECL1 (light blue), ECL2 (lime green), and ECL3 (turquoise) are highlighted as solid surfaces. b-e, Interaction details between sulfated CCK- 8 and CCK $_{\mathrm{A}} \mathrm{R}$. b, Recognition of CCK-8 by the three extracellular loops. c, Recognition of CCK-8 by the deep hydrophobic cavity beneath ECL3. d, Recognition of CCK-8 by the shallow hydrophobic cavity beneath ECL1 and ECL2. e, Recognition of CCK-8 by the bottom TMD region. Key interaction residues from $\mathrm{CCK}_{\mathrm{A}} \mathrm{R}$ are shown as green sticks, and the receptor is shown in cartoon presentation. Polar interactions are indicated as red dashed lines. f, Effects of mutations in the receptor ligand-binding pocket on CCK-8 binding activity assessed by a radiolabeled ligand binding assay $(n=3-4)$. Competition curves of mutants from ECL1, TM3, TM4 (left), ECL2, TM5, TM6 (middle), ECL3 and TM7 (right) compared to wild-type (WT) $\mathrm{CCK}_{\mathrm{A}} \mathrm{R}$ are shown. 

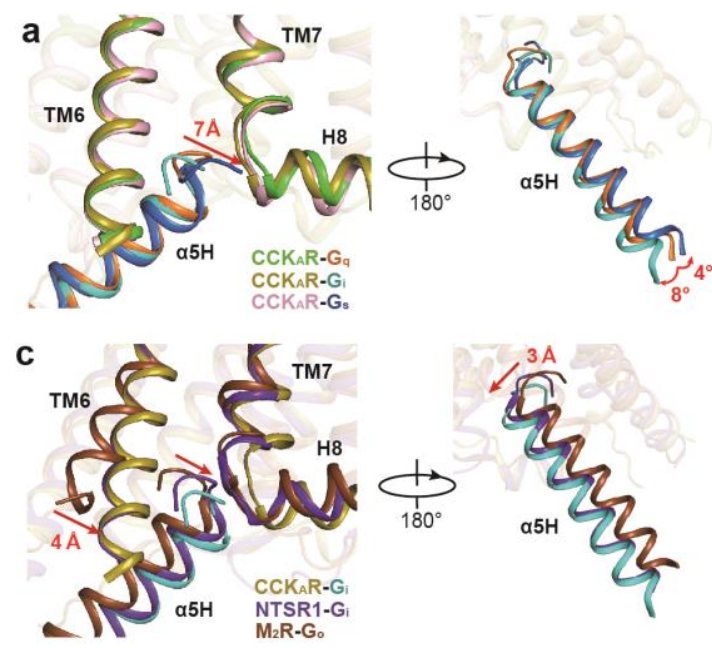
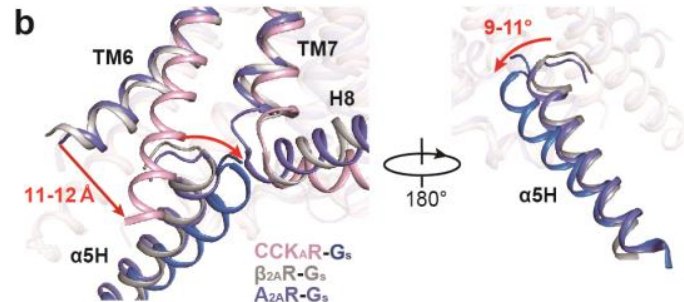

d
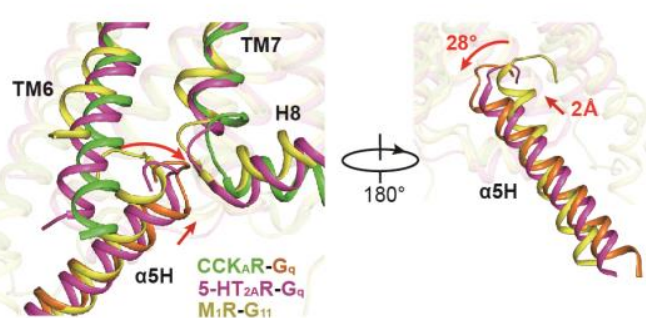

Fig. 3 Structural comparison of TM6 and $\alpha 5$ helix between $\mathrm{CCK}_{\mathrm{A}} \mathrm{R}-\mathrm{G}$ protein complexes and representative $\mathbf{G}_{\mathbf{s}^{-}}, \mathbf{G}_{\mathbf{q}^{-}}$, and $\mathbf{G}_{\mathrm{i}^{-}}$-coupled $\mathbf{G P C R}$ structures in two different views. a, Structural comparison of $\mathrm{CCK}_{\mathrm{A}} \mathrm{R}-\mathrm{G}_{\mathrm{q}}, \mathrm{CCK}_{\mathrm{A}} \mathrm{R}-\mathrm{G}_{\mathrm{s}}$, and $\mathrm{CCK}_{\mathrm{A}} \mathrm{R}-\mathrm{G}_{\mathrm{i}}$ complexes. A $7 \AA$ movement of the distal end of $\mathrm{G} \alpha_{\mathrm{s}} \alpha 5$ helix relative to that of $\mathrm{G} \alpha_{\mathrm{q}}$ and swing of $\mathrm{G} \alpha \alpha 5$ helix are highlighted as red arrows. b, Structural comparison of $\mathrm{CCK}_{\mathrm{A}} \mathrm{R}-\mathrm{G}_{\mathrm{s}}$ with $\beta_{2 \mathrm{~A}} \mathrm{R}-\mathrm{G}_{\mathrm{s}}$ and $\mathrm{A}_{2 \mathrm{~A}} \mathrm{R}-\mathrm{G}_{\mathrm{s}}$ complexes. Red arrows indicate an 11-12 $\AA$ displacement of TM6 and a 9-11 ${ }^{\circ}$ swing of $\mathrm{G} \alpha \alpha 5$ helix of $\mathrm{G}_{\mathrm{s}}$-coupled $\mathrm{CCK}_{\mathrm{A}} \mathrm{R}$ relative to $\mathrm{G}_{\mathrm{s}}$-coupled $\beta_{2 \mathrm{~A}} R$ and $A_{2 \mathrm{~A}} R$. c , Structural comparison of $C \mathrm{CK}_{\mathrm{A}} \mathrm{R}-\mathrm{G}_{\mathrm{i}}$ with NTSR1- $\mathrm{G}_{\mathrm{i}}$ and $\mathrm{M}_{2} \mathrm{R}-\mathrm{G}_{\mathrm{o}}$ complexes. A $4 \AA$ inward displacement of TM6 and a $3 \AA \mathrm{G} \alpha_{\mathrm{i}} \alpha 5$ helix shift of $\mathrm{G}_{\mathrm{q}}$-coupled $\mathrm{CCK}_{\mathrm{A}} \mathrm{R}$ in contrast to $\mathrm{G}_{0}$-coupled $\mathrm{M}_{2} \mathrm{R}$ are indicated as red arrows. d, Structural comparison of $\mathrm{CCK}_{\mathrm{A}} \mathrm{R}-\mathrm{G}_{\mathrm{q}}$ with 5-HT $\mathrm{H}_{2 \mathrm{~A}} \mathrm{R}-\mathrm{G}_{\mathrm{q}}$ and $\mathrm{M}_{1} \mathrm{R}-\mathrm{G}_{11}$ complexes. A $2 \AA$ upward movement of $\mathrm{G}_{\mathrm{q}}$ of $\mathrm{G}_{\mathrm{q}^{-}}$ coupled $\mathrm{CCK}_{\mathrm{A}} \mathrm{R}$ compared to $\mathrm{G}_{\mathrm{q}}$-coupled 5- $\mathrm{HT}_{2 \mathrm{~A}} \mathrm{R}$ and a $28^{\circ}$ rotation relative to $\mathrm{G}_{11}$-coupled $\mathrm{M}_{1} \mathrm{R}$ are highlighted as red arrows. The complex structures are aligned based on TM2-TM4 of the receptors. $\beta_{2 A} R-G_{s}, A_{2 A} R-G_{s}, N T S R 1-G_{i}, M_{2} R-G_{0}, 5-H_{2 A} R-G_{q}$, and $M_{1} R-G_{11}$ structures (PDB codes: 3SN6, 5G53, 6OS9, 6OIK, 6WHA, and 6OIJ) are colored in gray, marine, purple blue, dark brown, magenta, and yellow, respectively. 

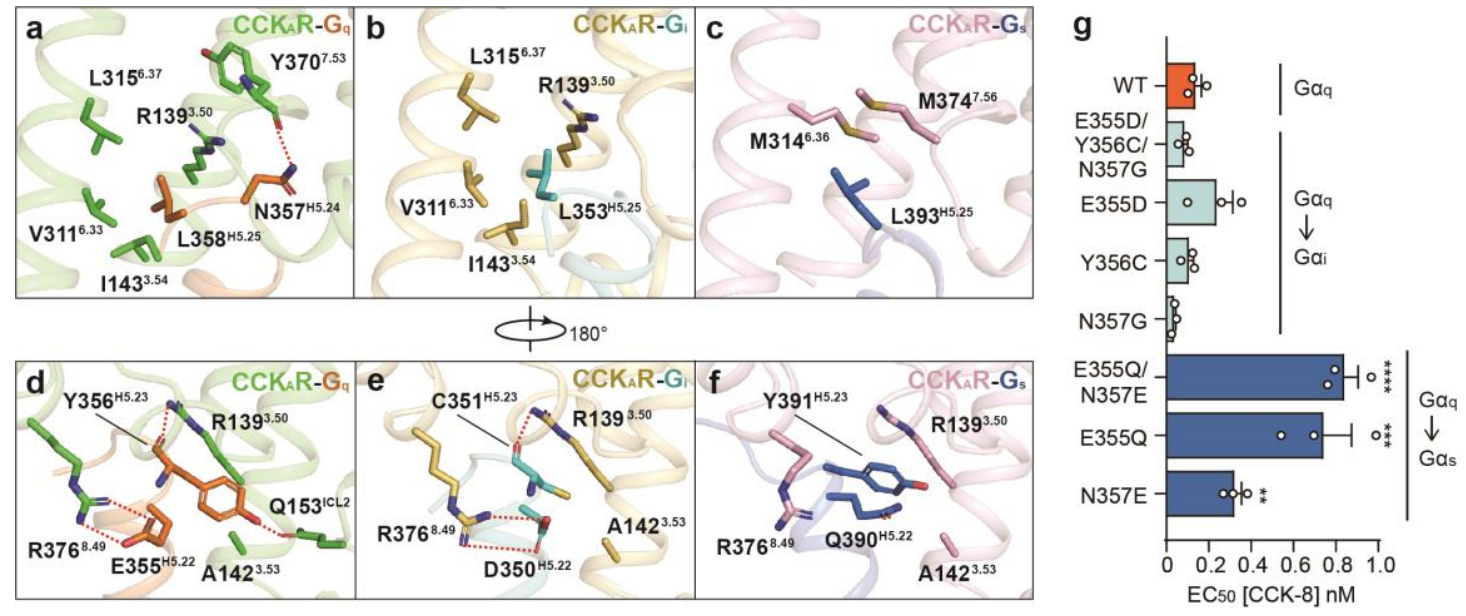

Fig. 4 Distinct interaction patterns of residues from the "wavy hook" motif. a-c, Interaction details between $\mathrm{CCK}_{\mathrm{A}} \mathrm{R}$ and $\mathrm{L} 358^{\mathrm{H} 5.25}$ and $\mathrm{N} 357^{\mathrm{H} 5.24}$ of $\mathrm{G} \alpha_{\mathrm{q}}(\mathbf{a}), \mathrm{L} 353^{\mathrm{H} 5.25}$ of $\mathrm{G} \alpha_{\mathrm{i}}(\mathbf{b})$, and $\mathrm{L} 393^{\mathrm{H} 5.25}$ of $\mathrm{G}_{\mathrm{s}}$ subunit (c). d-f, Interaction details between $\mathrm{CCK}_{\mathrm{A}} \mathrm{R}$ and $\mathrm{Y} 356^{\mathrm{H} 5.23}$ and $\mathrm{E} 355^{\mathrm{H} 5.22}$ of $\mathrm{G} \alpha_{\mathrm{q}}(\mathbf{d})$, $\mathrm{C} 351^{\mathrm{H} 5.23}$ and $\mathrm{D} 350^{\mathrm{H} 5.22}$ of $\mathrm{G} \alpha_{\mathrm{i}}(\mathbf{e})$, and $\mathrm{Y} 391^{\mathrm{H} 5.23}$ and Q $390^{\mathrm{H} 5.22}$ of $\mathrm{G} \alpha_{\mathrm{s}}$ subunit (f). H-bonds and salt bridges are indicated as red dashed lines. g, BRET assay evaluating the effects of "wavy hook" substitutions on $\mathrm{CCK}_{\mathrm{A}} \mathrm{R}-\mathrm{G}$ protein coupling. The "wavy hook" residues of the $\mathrm{G} \alpha_{\mathrm{q}}$ subunit were displaced by the corresponding residues in $\mathrm{G} \alpha_{\mathrm{s}}$ and $\mathrm{G} \alpha_{\mathrm{i}}$ subunits. All data were analyzed by oneway ANOVA. ${ }^{* * * *} P<0.0001,{ }^{* * *} P<0.001,{ }^{* *} P<0.01$. 


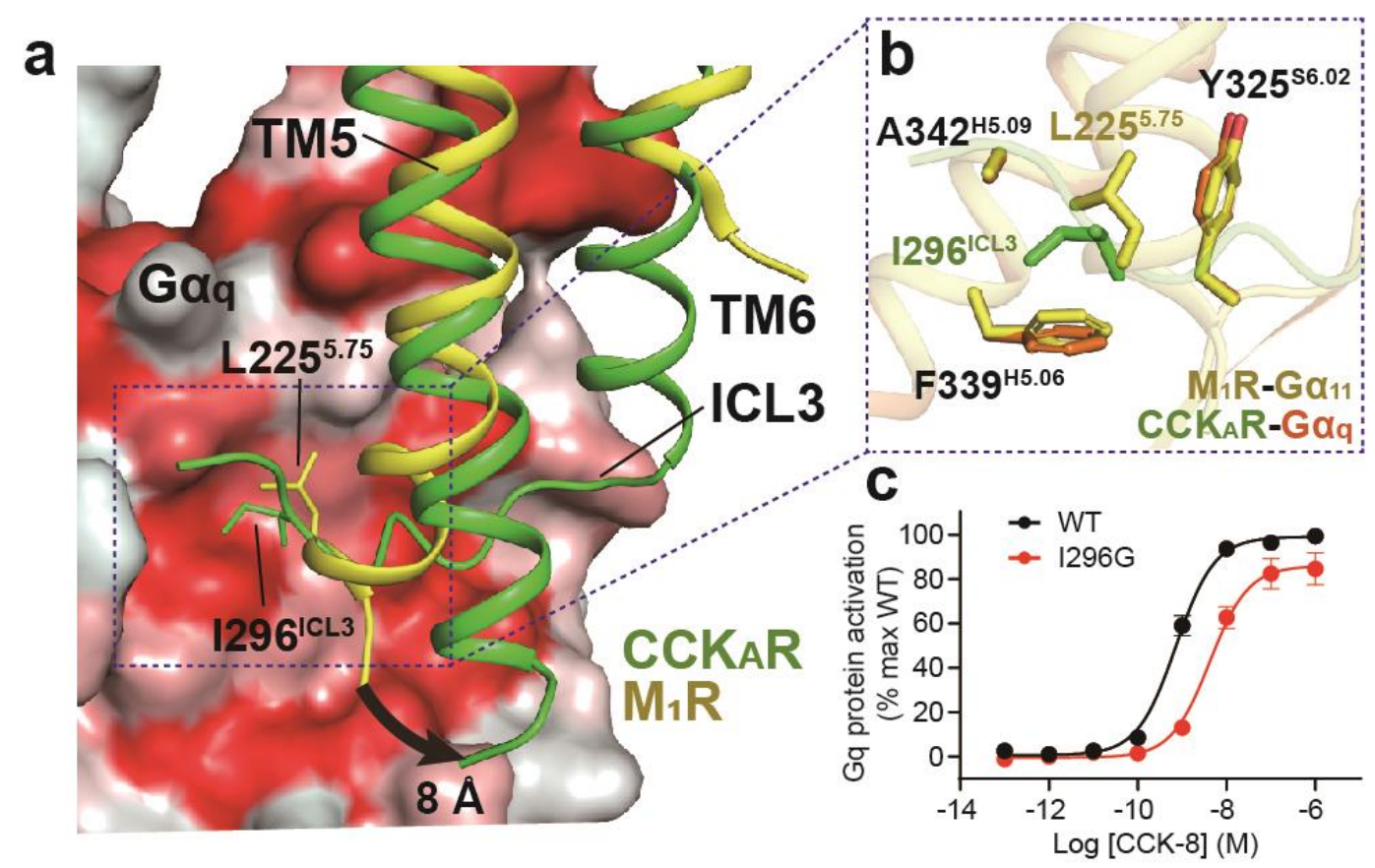

665 Fig. $5 \mid$ Interaction between ICL3 loop of $\mathbf{C C K}_{\mathrm{A}} \mathbf{R}$ and $\mathbf{G} \boldsymbol{\alpha}_{\mathbf{q}}$ subunit. a, I296 ${ }^{\mathrm{ICL} 3}$ of $C C K_{\mathrm{A}} \mathrm{R}$ and $\mathrm{L} 225^{5.75}$ of $\mathrm{M}_{1} \mathrm{R}$ occupy the same hydrophobic sub-pocket of the $\mathrm{G} \alpha$ subunit. The $\mathrm{G} \alpha_{\mathrm{q}}$ subunit is shown as a surface presentation by hydrophobicity (hydrophobic surface in red). An $8 \AA$ outward bend of TM5 of $\mathrm{CCK}_{A} \mathrm{R}$ relative to that of $\mathrm{M}_{1} \mathrm{R}$ is highlighted by a black arrow. b, Detailed interactions between $\mathrm{I} 296^{\mathrm{ICL} 3}\left(\mathrm{CCK}_{\mathrm{A}} \mathrm{R}\right) / \mathrm{L} 225^{5.75}\left(\mathrm{M}_{1} \mathrm{R}\right)$ and hydrophobic patch comprised by $670 \mathrm{Y} 325^{\mathrm{S} 6.02}, \mathrm{~F} 339^{\mathrm{H} 5.06}$, and $\mathrm{A} 342^{\mathrm{H} 5.09}$ of $\mathrm{G} \alpha_{\mathrm{q}}$ and $\mathrm{G} \alpha_{11}$ subunits. $\mathbf{c}$, BRET assay indicates that $\mathrm{I} 296 \mathrm{G}$ mutation decreases the association rate of $\mathrm{CCK}_{\mathrm{A}} \mathrm{R}$ with $\mathrm{G}_{\mathrm{q}}$ heterotrimer $(\mathrm{n}=3)$. WT, wild-type. 

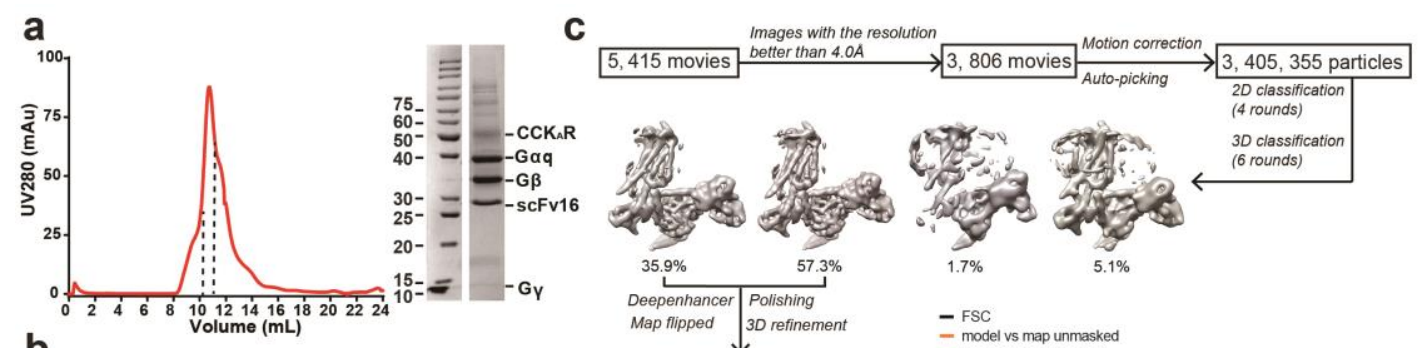

b
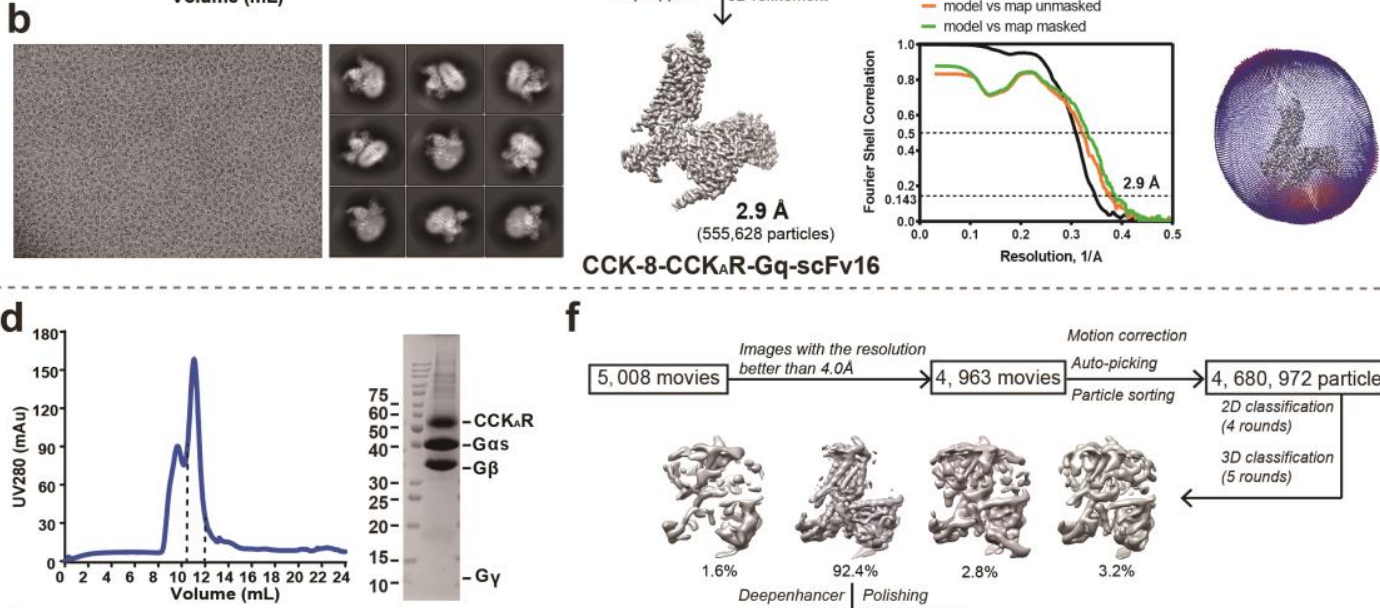

CCK-8-CCK $\mathrm{AR}_{\mathrm{A}} \mathrm{Gq}-\mathrm{ScFv} 16$

$f$
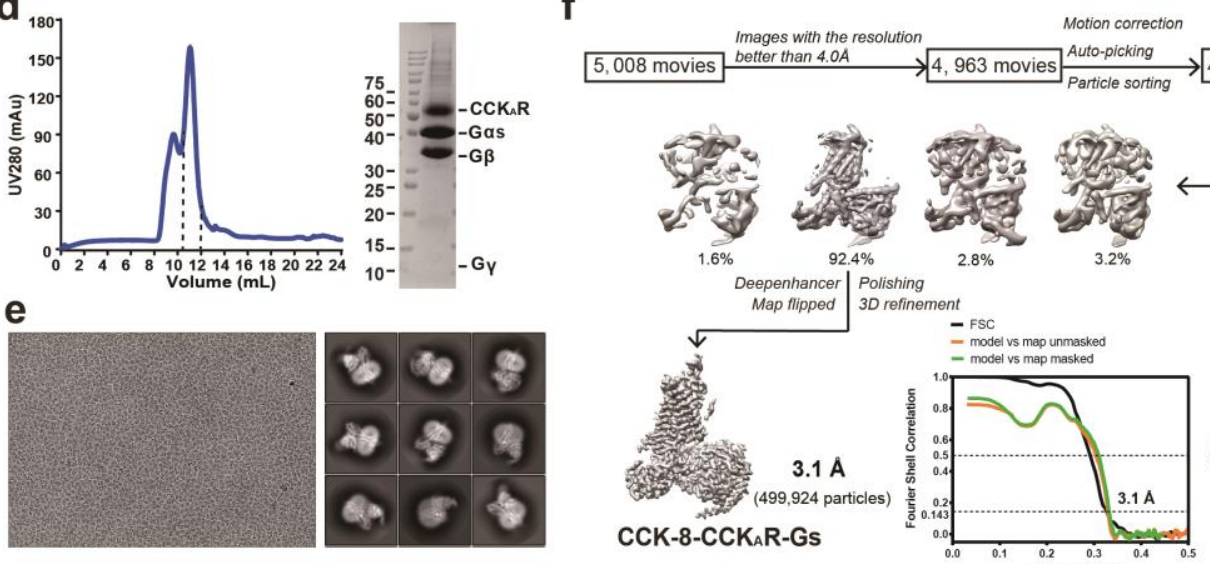

$4,680,972$ particles

$2 \mathrm{D}$ classification
(4 rounds)

$3 D$ classificatio (5 rounds)

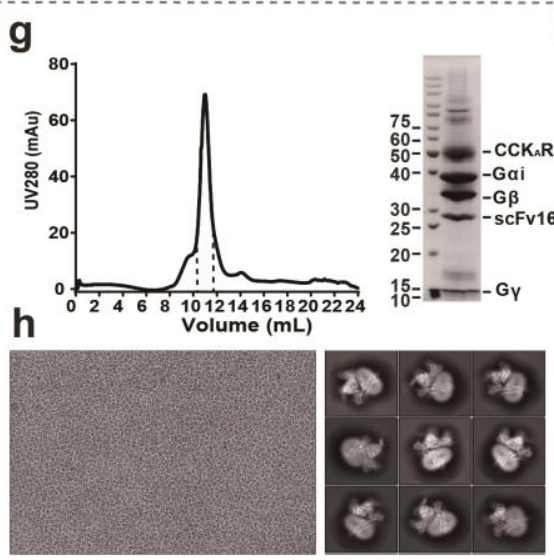

i

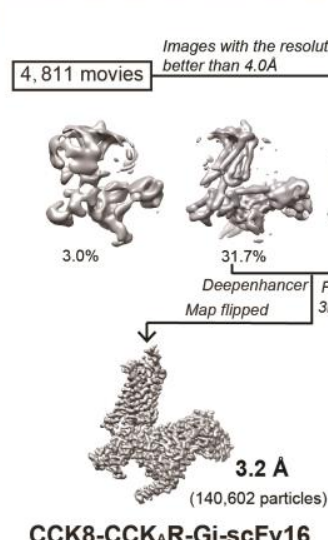

CCK8-CCKAR-Gi-scFv16
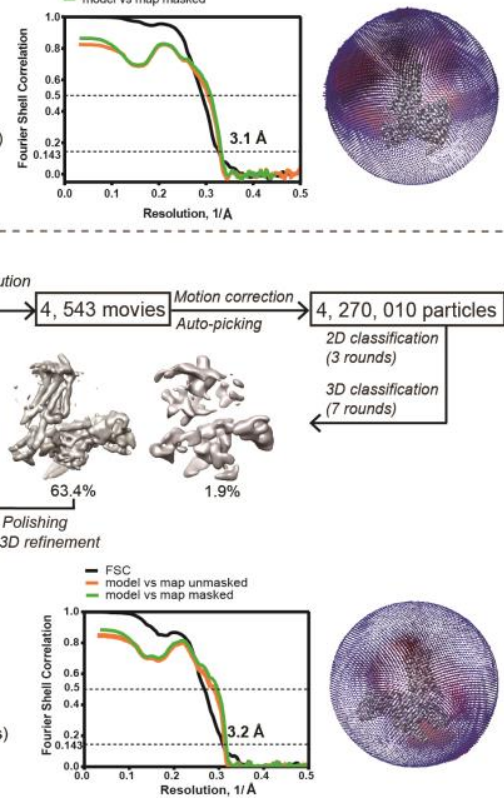
SDS-PAGE analysis of the CCK-8-CCK ${ }_{A} R-\mathrm{G}_{\mathrm{s}}$ protein complex sample. e, Representative cryoEM micrograph and 2D classification averages of the CCK-8-CCK $\mathrm{C}_{\mathrm{A}} \mathrm{R}-\mathrm{G}_{\mathrm{s}}$ complex. f, Singleparticle cryo-EM data processing flowcharts of the CCK-8-CCK ${ }_{A} R-G_{s}$ by Relion 3.0, including the Euler angle distribution of particles used in the final refinement and the fourier shell correlation (FSC) curves. The global resolution defined at the $\mathrm{FSC}=0.143$ is $3.1 \AA$. g, Size exclusion chromatography (SEC) profile and SDS-PAGE analysis of the CCK-8-CCK $\mathrm{A}-\mathrm{G}_{\mathrm{i}}-\mathrm{scFv} 16$ protein complex sample. h, Representative cryo-EM micrograph and 2D classification averages of the CCK-8-CCK ${ }_{A} \mathrm{R}-\mathrm{G}_{\mathrm{i}}-\mathrm{scFv} 16$ complex. i, Single particle cryo-EM data processing flowcharts of the CCK-8- $\mathrm{CCK}_{\mathrm{A}} \mathrm{R}-\mathrm{G}_{\mathrm{i}}-\mathrm{scFv} 16$ by Relion 3.0, including the Euler angle distribution of particles used in the final refinement and the fourier shell correlation (FSC) curves. The global resolution defined at the $\mathrm{FSC}=0.143$ is $3.2 \AA$. 


\section{a}

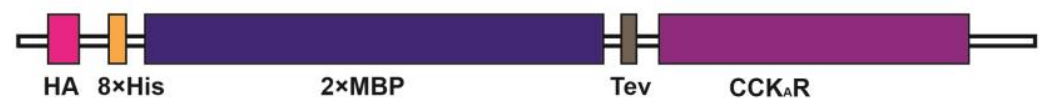

b

$\mathrm{G} \boldsymbol{\alpha}_{\mathrm{i}}$

MGCTLSAEDKAAVERSKMIDRNLREDGEKAAREVKLLLLGAGESGKSTIVKQMKIIH EAGYSEEECKQYKAVVYSNTIQSIIAI IRAMGRLKIDFGDSARADDARQLFVLAGAA EEGFMTAELAGVIKRLWKDSGVQACFNRSREYQLNDSAAYYLNDLDRIAQPNYIPTQ QDVLRTRVKTTGIVETHFTFKDLHFKMF DVGAQRSERKKWI HCFEGVTAI IFCVALS DYDLVLAEDEEMNRMHESMKLFDS ICNNKWFTDTS I ILFLNKKDLFEEKIKKSPLTI CYPEYAGSNTYEEAAAYIQCQFEDLNKRKDTKEIYTHFTCSTDTKNVQFVFDAVTDV I IKNNLKDCGLF

$\mathbf{G} \boldsymbol{\alpha}_{\mathrm{s}}$ MGCTLSAEDKAAVERSKMIEKQLQKDKQVYRATHRLLLLGADNSGKSTIVKQMRIYH VNGYSEEECKQYKAVVYSNTIQSIIAIIRAMGRLKIDFGDSARADDARQLFVLAGAA EEGFMTAELAGVIKRLWKDSGVQACFNRSREYQLNDSAAYYLNDLDRIAQPNYIPTQ QDVLRTRVKTSGIFETKFQVDKVNF HMF DVGAQRDERRKWIQCFNDVTAI I FVVDSS DY----------NRLQEALNDFKS IWNNRWLRT ISVILFLNKQDLLAEKVLAGKSKI EDYFPEFARYTT PEDATPEPGEDPRVTRAKYFIRDEFLRISTASGDGRHYCYPHFTC SVDTENARRIFNDCRDI IQRMHLRQYELL
$\mathrm{G} \boldsymbol{\alpha}_{\mathrm{q}}$
MGCTLSAEDKAAVERSKMIDRNLREDGEKARRELKLLLLGTGESGKSTFIKQMRIIH GSGYSDEDKRGFTKLVYQNIFTAMQAMIRAMDTLKIPYKYEHNKAHAQLVREVDVEK VSAFENPYVDAIKSLWNDPGIQECYDRRREYQLSDSTKYYLNDLDRVADPAYLPTQQ DVLRVRVPTTGI IEYPFDLQSVI FRMVDVGAQRSERRKWI HCFENVTS IMFLVALSE YDQVLVESDNENRMEESKALFRTIITYPWFQNSSVILFLNKKDLLEEKIMYSHLVDY FPEYDGPQRDAQAAREFILKMFVDLNPDSDKI IYSHFTCSTDTENIRFVFAAVKDTI LQLNLKEYNLV

Extended Data Fig. 2| Receptor and Ga subunits used in the cryo-EM structure determination. a, A schematic illustration of the $\mathrm{CCK}_{\mathrm{A}} \mathrm{R}$ construct used in cryo-EM studies. HA, hemagglutinin signal sequence; $2 \times M B P$, double-MBP tag. b. Protein sequences of $G \alpha_{q}, G \alpha_{s}$, and $\mathrm{G} \alpha_{\mathrm{i} 1}$ subunits. N-terminal sequence replaced in $\mathrm{G} \alpha_{\mathrm{s}}$ and $\mathrm{G} \alpha_{\mathrm{q}}$ is shown in blue. The two dominantnegative mutations are colored red and underlined. Stabilization mutations derived from the reported mini-G $\alpha_{s}$ are highlighted in cyan. AHD domain of the $G \alpha_{s}$ is replaced with the equivalent region of $\mathrm{G} \alpha_{\mathrm{i} 1}$ and colored in gray. 
a
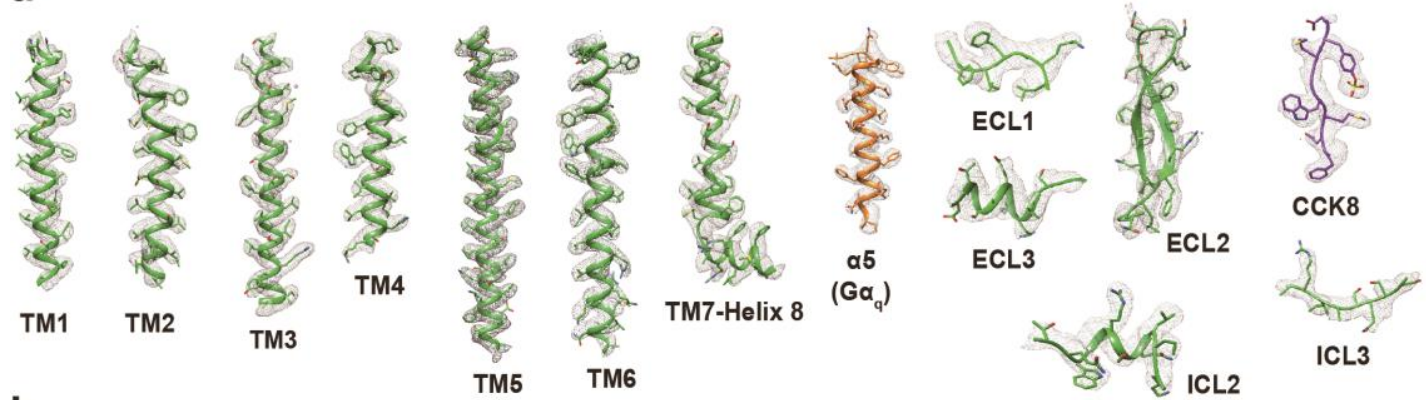

b
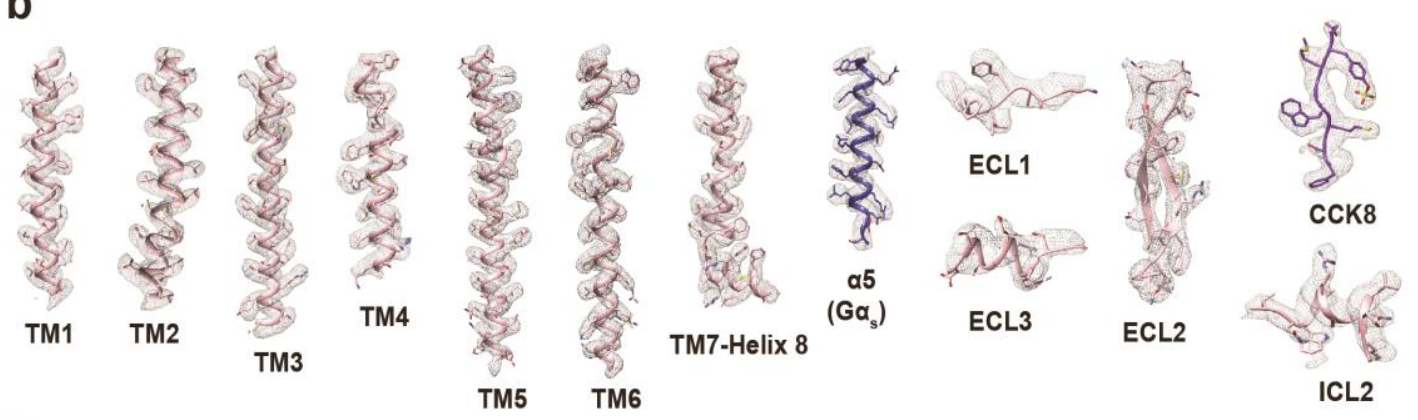

C
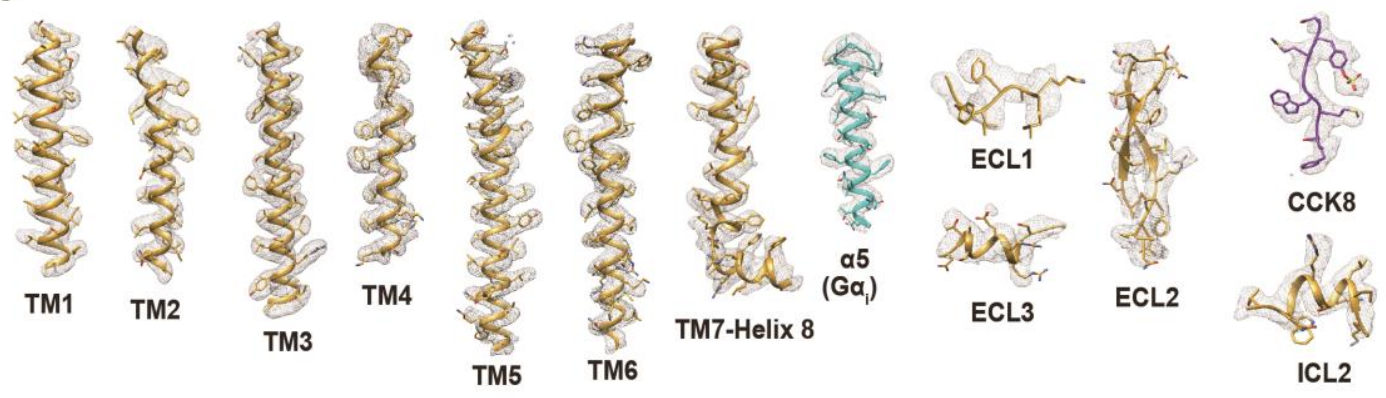

d

e
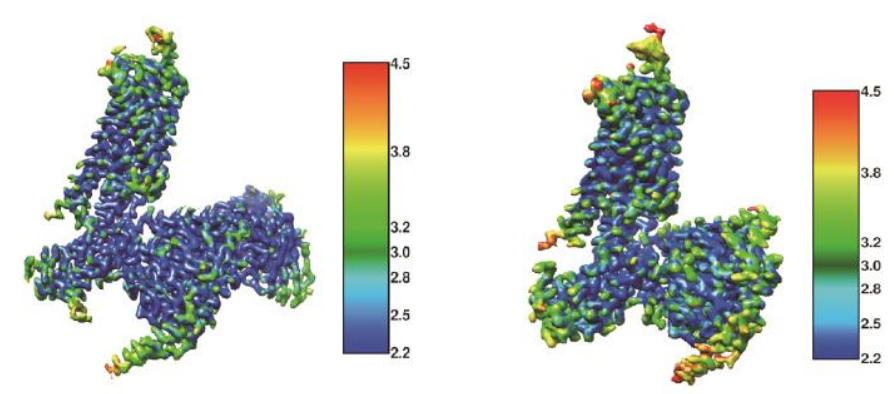

f

Extended Data Fig. 3 | Local cryo-EM density maps of $\mathrm{CCK}_{\mathrm{A}} \mathrm{R}-\mathrm{G}$ protein complexes. a, CryoEM density maps of TM1-TM7, ECL1-ECL3, ICL2, ICL3, CCK-8 peptide and $\alpha 5$ helix of G $\alpha_{\mathrm{q}}$ in the CCK-8-CCK $\mathrm{A}$ R- $\mathrm{G}_{\mathrm{q}}-\mathrm{ScF}$ 16 structure. b, Cryo-EM density maps of TM1-TM7, ECL1-ECL3, ICL2, CCK-8 peptide and $\alpha 5$ helix of $\mathrm{G} \alpha_{\mathrm{s}}$ in the CCK-8-CCK $\mathrm{A} R-\mathrm{G}_{\mathrm{s}}$ structure. c, Cryo-EM density maps of TM1-TM7, ECL1-ECL3, ICL2, CCK-8 peptide and $\alpha 5$ helix of $\mathrm{G}_{\mathrm{i}}$ in the CCK-8-CCK $\mathrm{A}_{\mathrm{A}}$ $\mathrm{G}_{\mathrm{i}}-\mathrm{scFv} 16$ structure. d-f, The global density maps of the CCK-8-CCK $\mathrm{A}$ - $-\mathrm{G}_{\mathrm{q}}-\mathrm{scF}$ 16 (d), CCK-8$\mathrm{CCK}_{\mathrm{A}} \mathrm{R}-\mathrm{G}_{\mathrm{s}}(\mathbf{e})$, and $\mathrm{CCK}-8-\mathrm{CCK}_{\mathrm{A}} \mathrm{R}-\mathrm{G}_{\mathrm{i}}-\mathrm{ScFv} 16$ (f) colored by local resolution $(\AA)$. The density maps are shown at thresholds of $0.08,0.055$ and 0.05 for the $C_{C K} R-G_{q}, C C K_{A} R-G_{s}$ and $C C K_{A} R-$ $\mathrm{G}_{\mathrm{i}}$ complex, respectively. 


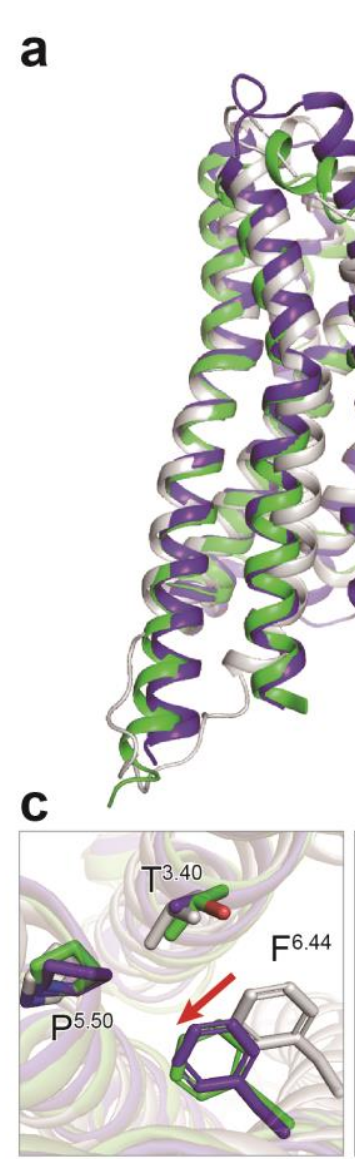

PIF motif
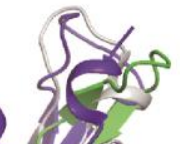

125
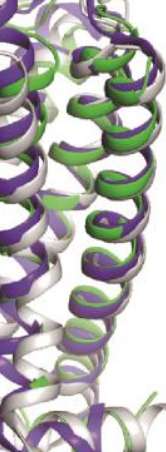

Active CCKAR

Active NTSR1

Inactive ghrelin receptor b

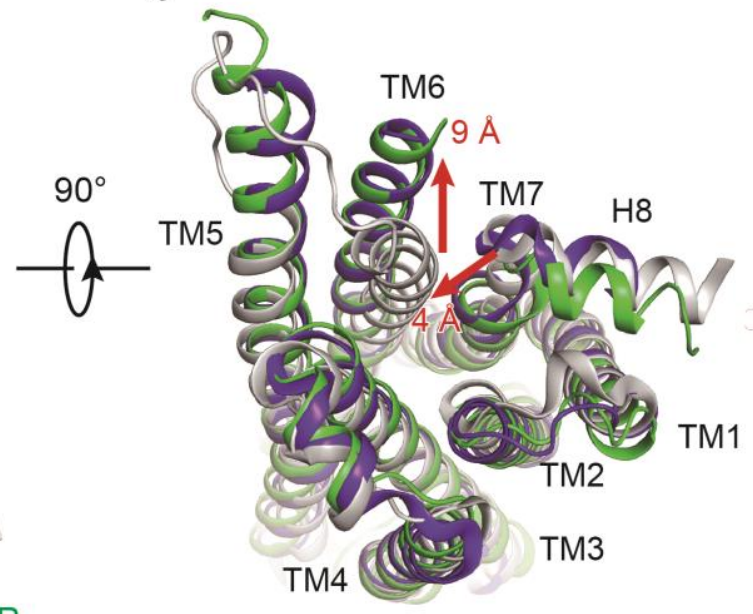

Extended Data Fig. 4 | Active conformation of $\mathbf{C C K}_{\mathbf{A}}$ R. a-b, Structural comparison of inactive

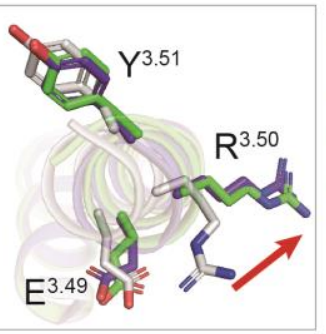

ERY motif

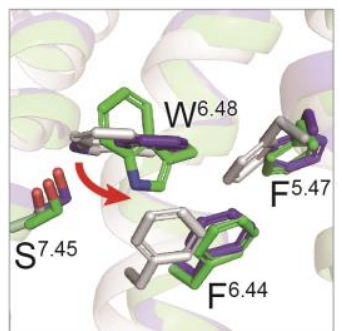

$\mathrm{CWxP}$

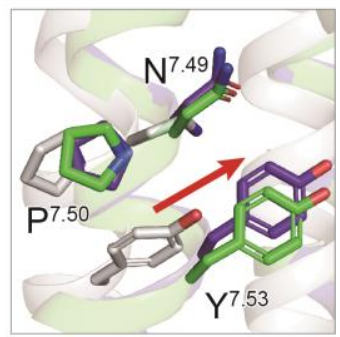

NPxxY motif ghrelin receptor (grey), active NTSR1 (purple blue), and active $\mathrm{CCK}_{\mathrm{A}} \mathrm{R}$ (green). Side view (a) and intracellular view (b) of the overall comparison are shown. c, Structural rearrangements of key activation motifs (PIF, ERY, CWxP, and $\mathrm{NPxxY}$ ) in $\mathrm{CCK}_{\mathrm{A}} \mathrm{R}$ compared to inactive GHSR and active NTSR1. NTSR1, neurotensin receptor 1. 


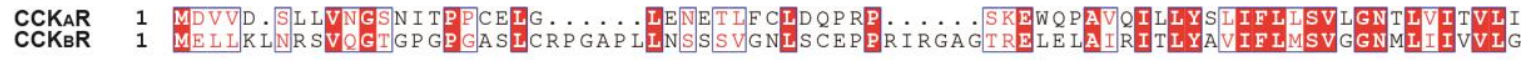

N-terminus

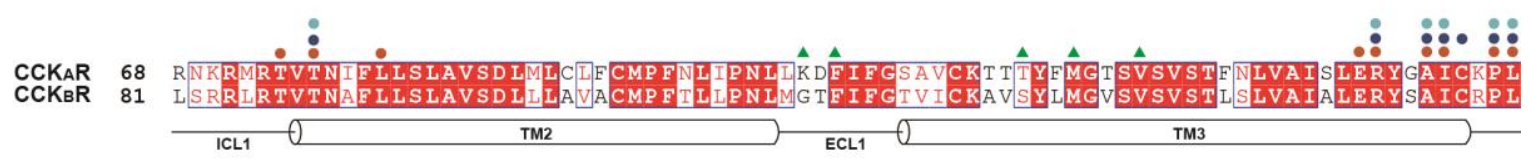

$\because: 8$

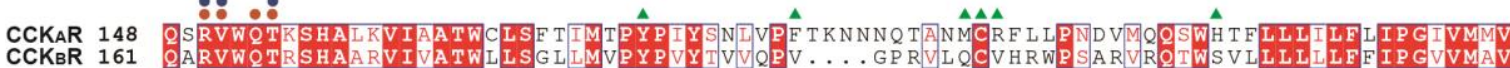

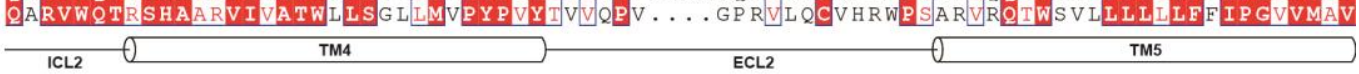

$:$

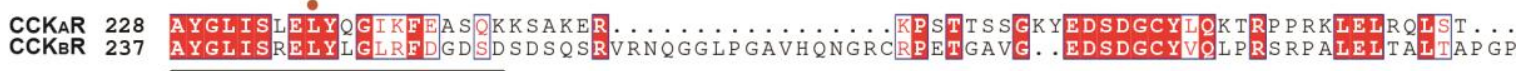
TM5
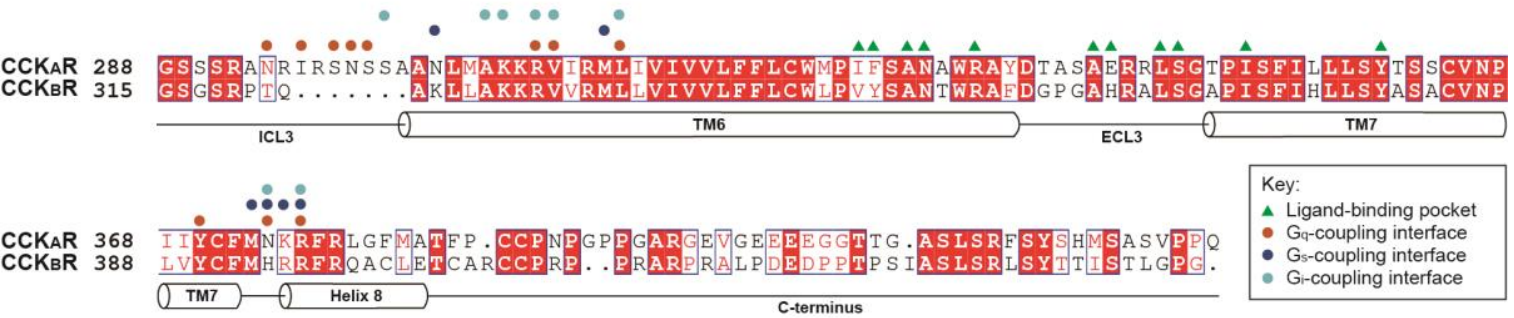

Extended Data Fig. 5 | Sequence alignment of CCK receptors. Helical secondary structures are shown based on $\mathrm{CCK}_{\mathrm{A}} \mathrm{R}$. Residues involved in ligand-binding are labeled with green triangles. Residues involved in $\mathrm{G}$ protein coupling are labeled with circles (orange, $\mathrm{G}_{\mathrm{q}}$; blue, $\mathrm{G}_{\mathrm{s}}$; cyan, $\mathrm{G}_{\mathrm{i}}$ ). 


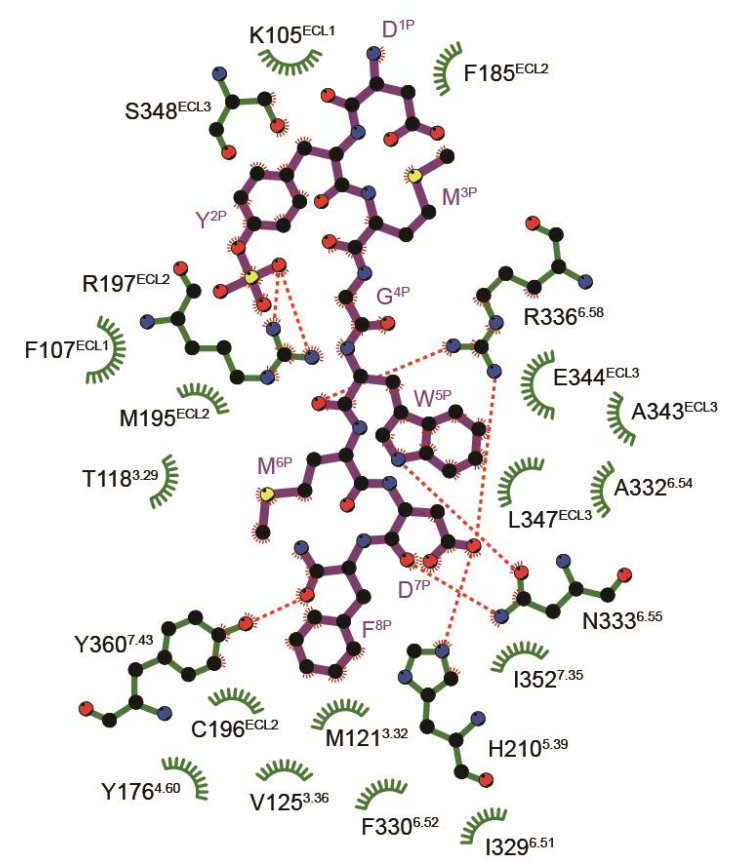

Extended Data Fig. 6 | 2D interaction plot of $\mathrm{CCK}_{\mathrm{A}} \mathrm{R}$ recognition by sulfated CCK-8. Residues in the ligand-binding pocket are colored in green. CCK-8 is displayed as magenta sticks. Polar interactions are indicated as red dashed lines. 


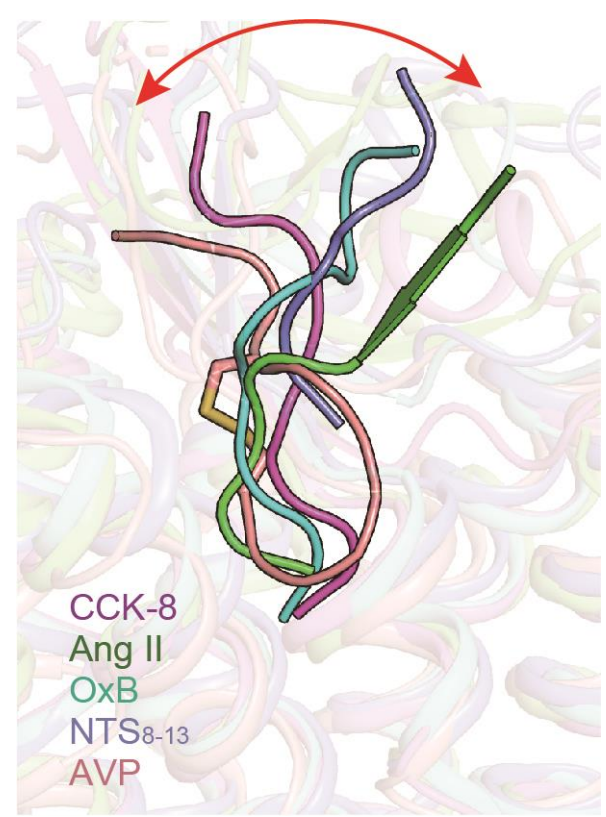

Extended Data Fig. 7 | Structure comparison of CCK-8 with other neuropeptides solved to date. The neuropeptides are shown as a cartoon. The shift of the extracellular part of neuropeptides is highlighted as a red arrow. CCK-8 in the CCK-8- $\mathrm{CCK}_{\mathrm{A}} \mathrm{R}-\mathrm{G}_{\mathrm{q}}$ complex structure, magenta; Ang II, angiotensin II (PDB: 6OS0), green; OxB, orexin B (PDB: 7L1U), cyan; NTS 8 -13, neurotensin 813 (PDB: 6OS9), purple blue; AVP, arginine vasopressin (PDB: 7DW9), salmon. 
a
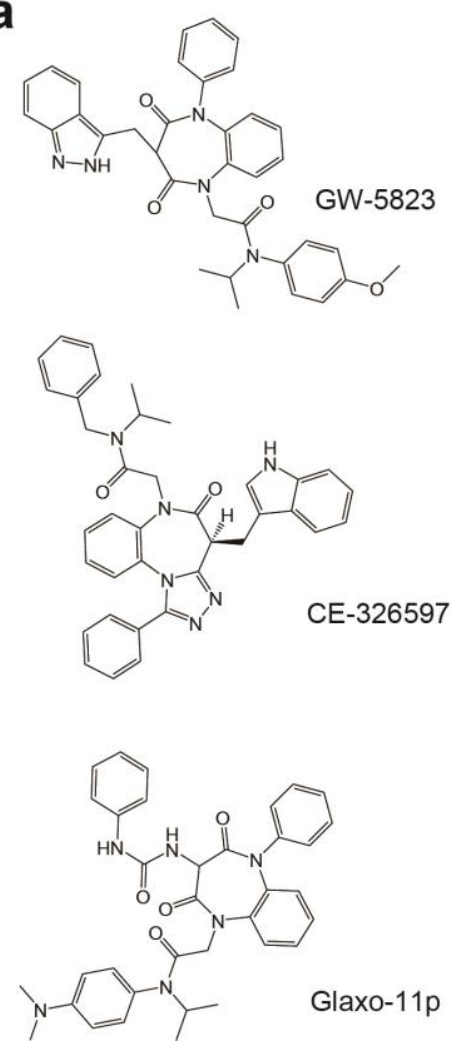

b

CCK-8

GW-5823

CE-326597

Glaxo-11p
CCKAR

Extended Data Fig. 8 | Molecular docking of small molecule agonists to the $\mathrm{CCK}_{\mathrm{A}} \mathrm{R}$ structure.

a, Chemical structures of small molecule agonists of $\mathrm{CCK}_{\mathrm{A}} \mathrm{R}$. $\mathbf{b}$, Comparison of the binding poses of three agonists with CCK-8. CCK-8, magenta; GW-5823, orange; CE-326597, grey; Glaxo-11p, purple blue. CCK-8 and small molecule agonists are shown as sticks. The amino acids of CCK-8 are labelled. 


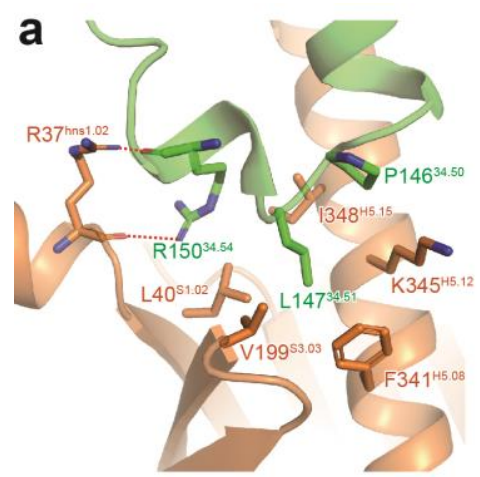

$\mathrm{CCK}_{\mathrm{A}} \mathrm{R}-\mathrm{G}_{9}$

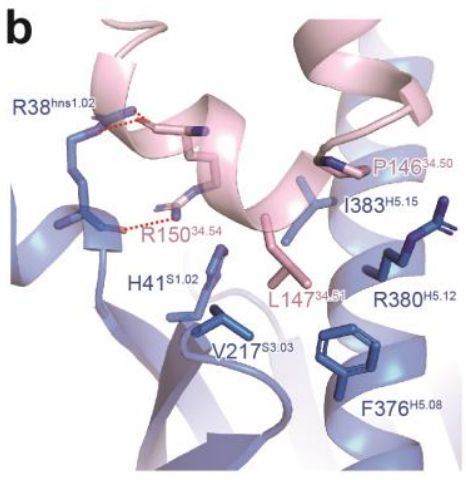

$\mathrm{CCK}_{\mathrm{A}} \mathrm{R}-\mathrm{G}_{\mathrm{s}}$

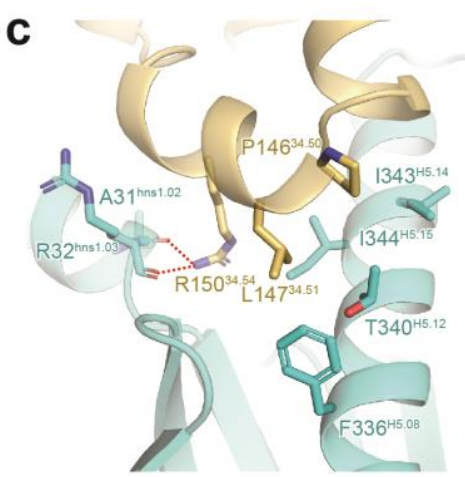

CCKAR-G

Extended Data Fig. 9 | The interface between CCK $_{\mathrm{A}} \mathrm{R}$ ICL2 and different G proteins. Detailed interaction between the receptor and $\mathrm{G} \alpha_{\mathrm{q}}(\mathbf{a}), \mathrm{G} \alpha_{\mathrm{s}}(\mathbf{b})$, and $\mathrm{G} \alpha_{\mathrm{i}}(\mathbf{c})$ are shown. Side chains of related residues are shown as sticks. 

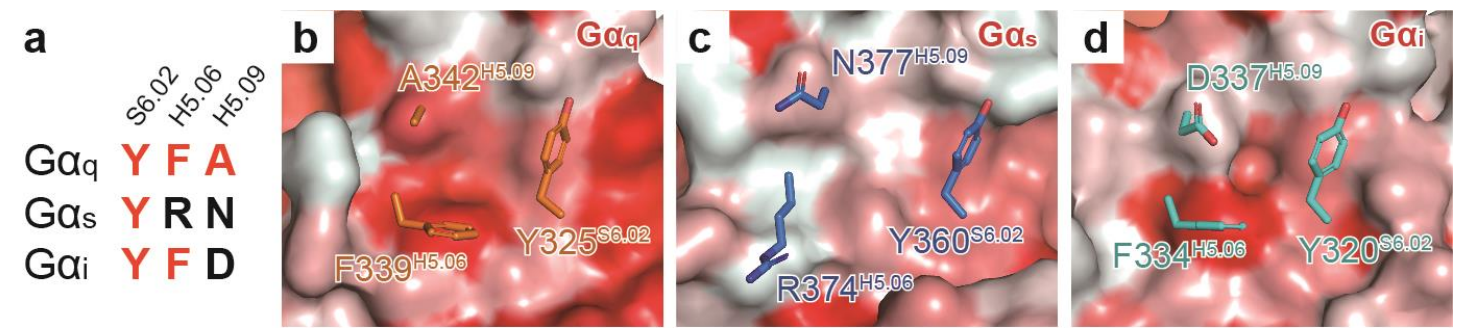

Extended Data Fig. 10| Comparison of the hydrophobic patch in $\mathrm{Ga}_{\mathrm{q}}$ subunit to the corresponding sites in other G proteins. a, Sequence alignment of S6.02, H5.06, and H5.09 from $\mathrm{G} \alpha_{\mathrm{q}}, \mathrm{G} \alpha_{\mathrm{s}}$, and $\mathrm{G} \alpha_{\mathrm{i}}$ subunits. Residues at positions S6.02, H5.06, and H5.09 comprise the hydrophobic patch to interact with $\mathrm{CCK}_{\mathrm{A}} \mathrm{R}$ ICL3. b-d, Surface presentation of the patch by hydrophobicity. Side chains of residues at positions S6.02, H5.06, and H5.09 in $G \alpha_{\mathrm{q}}(\mathbf{b}), \mathrm{G} \alpha_{\mathrm{s}}(\mathbf{c})$, and $\mathrm{G} \alpha_{\mathrm{i}}(\mathbf{d})$ subunits are shown. 
Extended Data Table 1 | Cryo-EM data collection, refinement and validation statistics.

\begin{tabular}{|c|c|c|c|}
\hline & $\mathrm{CCK}_{\mathrm{A}} \mathrm{R} / \mathrm{G}_{\mathrm{q}} / \mathrm{scFv16}$ & $\mathbf{C C K}_{\mathrm{A}} \mathbf{R} / \mathbf{G}_{\mathrm{s}}$ & $\mathrm{CCK}_{\mathrm{A}} \mathrm{R} / \mathrm{G}_{\mathrm{i} 1} / \mathrm{scFv16}$ \\
\hline \multicolumn{4}{|l|}{ Data collection and processing } \\
\hline Magnification & 81,000 & 81,000 & 81,000 \\
\hline Voltage $(\mathrm{kV})$ & 300 & 300 & 300 \\
\hline Electron exposure (e-/ Å2) & 80 & 80 & 80 \\
\hline Defocus range $(\mu \mathrm{m})$ & $-0.5 \sim-3.0$ & $-0.5 \sim-3.0$ & $-0.5 \sim-3.0$ \\
\hline Pixel size $(\AA)$ & 1.045 & 1.045 & 1.045 \\
\hline Symmetry imposed & $\mathrm{C} 1$ & $\mathrm{C} 1$ & $\mathrm{C} 1$ \\
\hline Initial particle projections (no.) & $3,405,355$ & $4,680,972$ & $4,270,010$ \\
\hline Final particle projections (no.) & 555,628 & 499,924 & 140,602 \\
\hline Map resolution $(\AA)$ & 2.9 & 3.1 & 3.2 \\
\hline FSC threshold & 0.143 & 0.143 & 0.143 \\
\hline Map resolution range $(\AA)$ & $2.3-4.3$ & $2.3-4.3$ & $2.3-4.3$ \\
\hline \multicolumn{4}{|l|}{ Refinement } \\
\hline Initial model used & $6 \mathrm{OIJ}$ & $6 \mathrm{NBF}$ & $6 \mathrm{OMM}$ \\
\hline \multicolumn{4}{|l|}{ (PDB accession number) } \\
\hline Model resolution $(\AA)$ & 3.0 & 3.2 & 3.4 \\
\hline FSC threshold & 0.5 & 0.5 & 0.5 \\
\hline Map sharpening B-factor $(\AA 2)$ & -97.47 & -134.32 & -111.38 \\
\hline \multicolumn{4}{|l|}{ Model composition } \\
\hline Non-hydrogen atoms & 8999 & 7196 & 8860 \\
\hline Protein residues & 1170 & 922 & 1153 \\
\hline \multicolumn{4}{|l|}{ B-factors $(\AA 2)$} \\
\hline Protein & 56.03 & 66.86 & 63.12 \\
\hline \multicolumn{4}{|l|}{ RMSD } \\
\hline Bond lengths $(\AA)$ & 0.010 & 0.010 & 0.002 \\
\hline Bond angles $\left(^{\circ}\right)$ & 1.027 & 1.010 & 0.625 \\
\hline \multicolumn{4}{|l|}{ Validation } \\
\hline MolProbity score & 1.45 & 1.39 & 1.35 \\
\hline Clashscore & 4.50 & 3.85 & 2.45 \\
\hline Rotamer outliers (\%) & 0.21 & 0.26 & 0.00 \\
\hline \multicolumn{4}{|l|}{ Ramachandran Plot } \\
\hline Favored (\%) & 96.51 & 96.57 & 95.40 \\
\hline Allowed (\%) & 3.49 & 3.43 & 4.60 \\
\hline Disallowed (\%) & 0.00 & 0.00 & 0.00 \\
\hline
\end{tabular}




\section{Extended Data Table 2 | Effects of mutations in the ligand-binding pocket of $\mathrm{CCK}_{\mathrm{A}} \mathrm{R}$ on CCK-} 8 binding affinities.

Radiolabeled ligand ([$\left.\left.{ }^{1251}\right] \mathrm{CCK}-8\right)$ binding assay was performed to evaluate the ligand binding affinity of $\mathrm{CCK}_{\mathrm{A}} \mathrm{R}$ mutants. Data represent mean $\mathrm{pKi} \pm$ S.E.M. Experiments were performed in triplicate $(\mathrm{n}=3-4) . * P<0.05$ versus wild-type (WT). N.D., not determined. FACS analyses were performed to evaluate the surface expression of the $\mathrm{CCK}_{\mathrm{A}} \mathrm{R}$ mutants.

\begin{tabular}{ccc}
\hline Mutant & pKi \pm S.E.M. & Expression \% \\
\hline WT & $8.58 \pm 0.12$ & 100 \\
K105A & $7.78 \pm 0.22$ & $77.86 \pm 6.24$ \\
F107A & N.D. & $71.85 \pm 6.84$ \\
T118A & $8.73 \pm 0.13$ & $78.06 \pm 5.38$ \\
M121A & $8.03 \pm 0.15$ & $74.99 \pm 5.48$ \\
V125A & $8.68 \pm 0.12$ & $46.48 \pm 1.03$ \\
Y176A & N.D. & $26.63 \pm 2.43$ \\
F185A & $7.98 \pm 0.24$ & $77.98 \pm 4.85$ \\
M195A & $8.10 \pm 0.26$ & $85.45 \pm 4.52$ \\
C196A & N.D. & $3.24 \pm 0.06$ \\
R197A & N.D. & $104.14 \pm 5.14$ \\
H210A & $8.61 \pm 0.12$ & $81.19 \pm 4.32$ \\
I329A & N.D. & $74.22 \pm 7.37$ \\
F330A & $8.67 \pm 0.09$ & $27.31 \pm 2.74$ \\
A332G & $8.43 \pm 0.12$ & $32.50 \pm 4.21$ \\
N333A & N.D. & $63.96 \pm 3.31$ \\
R336A & N.D. & $82.96 \pm 5.35$ \\
A343G & N.D. & $50.61 \pm 5.37$ \\
E344A & N.D. & $88.00 \pm 13.77$ \\
L347A & N.D. & $52.59 \pm 1.43$ \\
S348A & N.D. & $98.35 \pm 8.18$ \\
I352A & N.D. & $80.35 \pm 1.26$ \\
Y360A & $8.00 \pm 0.09$ & $82.85 \pm 6.85$ \\
\hline & & \\
\hline
\end{tabular}




\section{Extended Data Table 3 | Coupling activity of $\mathrm{CCK}_{\mathrm{A}} \mathrm{R}$ with different $\mathrm{G}$ proteins.}

BRET assay was performed to evaluate the coupling activity of $\mathrm{CCK}_{\mathrm{A}} \mathrm{R}$ with different $\mathrm{G}$ proteins. Data represent mean $\mathrm{pEC}_{50} \pm$ S.E.M. Decreased fold of $E_{\max }$ compared to $\mathrm{G}_{\mathrm{q}}$ was calculated.

780 Radiolabeled ligand binding assay was used to evaluate the allosteric effects of different G proteins on the binding affinity of CCK-8. The binding affinities are indicated as $\mathrm{pKi} \pm$ S.E.M. All data were analyzed by two-tailed Student's $t$-test. $* P<0.05$ versus receptor. Experiments were performed in triplicate $(n=3)$.

\begin{tabular}{cccc}
\hline Group & pEC $_{\mathbf{5 0}} \pm$ S.E.M. & $\begin{array}{c}\text { Decreased fold } \\
\text { of } \boldsymbol{E}_{\text {max }}\end{array}$ & pKi \pm S.E.M. \\
\hline Receptor & - & - & $7.92 \pm 0.06$ \\
\hline Receptor $+\mathrm{G}_{\mathrm{q}}$ & $8.42 \pm 0.08$ & 1 & $8.28 \pm 0.08^{*}$ \\
Receptor $+\mathrm{G}_{\mathrm{i}}$ & $7.32 \pm 0.22$ & 6.60 & $7.87 \pm 0.07$ \\
Receptor $+\mathrm{G}_{\mathrm{s}}$ & $7.92 \pm 0.65$ & 20.33 & $8.02 \pm 0.06$ \\
\hline
\end{tabular}




\section{Extended Data Table $4 \mid$ Effect of $1296 \mathrm{G}$ mutation of $\mathrm{CCK}_{\mathrm{A}} \mathrm{R}$ on $\mathrm{G}$ protein-coupling activity.} BRET based NanoBiT G-protein recruitment and NanoBiT G-protein dissociation assays were performed to evaluate $\mathrm{G}_{\mathrm{q}^{-}}, \mathrm{G}_{\mathrm{i}^{-}}$, and $\mathrm{G}_{\mathrm{s}}$-coupling activity, respectively. Data represent mean $\mathrm{pEC}_{50}$ \pm S.E.M. $* * P<0.01$ versus wild-type (WT). FACS analyses were performed to evaluate the surface expression of $\mathrm{CCK}_{\mathrm{A}} \mathrm{R}$ mutant. Radiolabeled ligand binding assay was used to evaluate the effects of the mutation on the binding affinity of CCK-8. The binding affinities are indicated as $\mathrm{pKi} \pm$ S.E.M. All data were analyzed by two-tailed Student's $t$-test. Experiments were performed in triplicate $(n=3)$.

\begin{tabular}{cccccc}
\hline \multirow{2}{*}{ Mutant } & \multicolumn{3}{c}{ pEC $_{\mathbf{5 0}} \pm$ S.E.M. } & \multirow{2}{*}{ Expression \% } & pKi \pm S.E.M. \\
\cline { 2 - 5 } & $\mathbf{G}_{\mathbf{q}}$ & $\mathbf{G}_{\mathbf{i}}$ & $\mathbf{G}_{\mathbf{s}}$ & & \\
\hline WT & $9.14 \pm 0.04$ & $6.81 \pm 0.12$ & $10.48 \pm 0.10$ & 100 & $8.58 \pm 0.12$ \\
I296G & $8.38 \pm 0.09^{* *}$ & $6.66 \pm 0.08$ & $10.46 \pm 0.20$ & $99.52 \pm 3.10$ & $8.63 \pm 0.13$ \\
\hline
\end{tabular}

